\title{
LA INTENDENCIA DE MARINA Y EL «GOBIERNO DE LA CONTRATACIÓN»: EL SUEÑO NAVAL DE JOSÉ PATIÑO Y ROSALES (1717-1736)
}

\author{
The Intendance of Navy and the "Government of the \\ Board of Trade»: The Naval Dream of José Patiño y Rosales \\ (1717-1736)
}

\section{Ana CRESPO SOLANA}

Instituto de Historia, Consejo Superior de Investigaciones Científicas

Correo-e: ana.crespo@cchs.csic.es

RESUMEN: Terminada la Guerra de Sucesión por la corona de España en 1713, se experimentó una fuerte constatación de que las instituciones del comercio colonial americano acuciaban graves problemas en su configuración interna, es una crisis institucional en una época en la que se desea forzar la centralización del Estado y las administraciones, pero sobre todo en relación a dos aspectos: el fiscal y el organizativo. En este escenario, José Patiño y Rosales (1666-1736) unificará los planes y discursos de otros estadistas y marinos, como Andrés de Pes, José Campillo, Manuel García de Bustamante o Bernardo Tinajero de la Escalera, para convertir los clásicos planes de refuerzo del comercio colonial a través de compañías de comercio en un auténtico plan de desarrollo naval en la bahía de Cádiz en cooperación con otros ministros, como el propio Francisco de Varas y Valdés que, aunque receloso de los problemas fiscales de Cádiz, cooperó con Patiño en la reactivación de la navegación atlántica de la Carrera de Indias.

Palabras clave: Comercio Colonial; Armada española; Casa de la Contratación; Construcción naval moderna; Historia naval; siglo XviII. 
ANA CRESPO SOLANA

LA INTENDENCIA DE MARINA Y EL «GOBIERNO DE LA CONTRATACION»: EL SUEÑO NAVAL DE JOSÉ PATIÑO Y ROSALES (1717-1736)

ABSTRACT: After the War of Succession in 1713 the government of the Hispanic Monarchy was conscious about the crisis of the American colonial trade. Besides there was serious problems related to the internal configuration and the organization and maintenance of the Navy. That was an institutional crisis in an era in which the Spanish Crown desired to force the centralization of the State and administrations, but especially in relation to two aspects: the fiscal and the administration of the Armadas. In this scenario, José Patiño y Rosales (1666-1736) will unify the plans and political discourses from former statesmen and Seamen, such as Andrés de Pes, José Campillo, Manuel García de Bustamante or Bernardo Tinajero de la Escalera, to convert the classic reinforcement plans of colonial commerce through trading companies in an authentic naval development plan in the bay of Cadiz in cooperation with other ministers, such as Francisco de Varas and Valdés who, although distrustful of the fiscal problems of Cadiz, he cooperated with Patiño in order to reactivate the Atlantic navigation of the Carrera de Indias.

Key words: Colonial Trade; Spanish Armada; Board of Trade; Early Modern Shipbuilding; Naval History; $18^{\text {th }}$ Century.

El denominado pleito por el traslado de la Casa de la Contratación entre Sevilla y Cádiz tuvo en realidad unos largos antecedentes que se remontaban a la época de las rivalidades por la constitución de la cabecera oficial del apresto de flotas y armadas, así como puerto seguro para arribadas y retornos. El proceso se contextualizó en una larga historia de naufragios, pérdidas de barcos mercantes y cargamentos, negligencia en la construcción y apresto de bajeles, falta de coordinación en las múltiples arribadas forzosas en puertos distintos a los estipulados, así como asedios por parte de armadas inglesas y holandesas que habían derivado en el fortalecimiento de fuertes, castillos y defensas marítimo-militares en la ciudad portuaria. Eventos históricos que en suma producían recelos políticos entre los defensores de las elites aristocráticas del Reino de Castilla; y desconfianza económica en las redes mercantiles extranjeras que tenían sus bases en Sevilla y que empezaron a desplazar socios y consignatarios a la Bahía de Cádiz, incluyendo los antepuertos de Sanlúcar de Barrameda y de El Puerto de Santa María.

Aunque la situación favorable de Cádiz desde el punto de vista geográfico y fiscal era algo evidente desde los primeros tiempos del sistema que rigió el comercio y la navegación española ${ }^{1}$, todos los estudios coinciden en las evidencias notables

1. Véase resumen en Bustos Rodríguez, M.: «Cadix, temps et destin d'une ville atlantique à l'époque moderne (Xvie-XVIIe siècles)», La Ville maritime. Temps, especes et représentations. 
que luego defendería José Patiño: el carácter geográfico de la bahía como carenero y puerto de abrigo, que superaba con creces los problemas de la barra de Sanlúcar. Ello era paralelo a la realidad del «emporio del Orbe» desde la década de 1660, cuando las casas comerciales europeas trasladaron sus socios y consignatarios a Cádiz, además de producirse la transmigración de una gran cantidad de miembros de familias de mercaderes extranjeros. Es muy posible que estos mercaderes hicieran presiones para beneficiar a sus socios y a ellos mismos en los negocios de importación, arribadas y consignación de navíos. Estas circunstancias podrían parecer simples, pero lo cierto es que entretejen un complejo mapa de acontecimientos históricos que aún plantean enigmas para la investigación, como el caso del episodio del mercader Francisco Báez Eminente, su arriendo de las aduanas y la disparidad de tasas que esto produjo con Sevilla y el incremento de las aportaciones a la Real Hacienda desde Cádiz². Ya a partir de 1635 había empezado a institucionalizarse el indulto para comprar el perdón de los fraudes ${ }^{3}$. Es hipotético pensar que la disminución de los derechos de aduanas en 1661 fuese una alternativa más sensata a dicho indulto: la reducción del Almojarifazgo de Indias, y el «Mayor»; en 1667, la bajada de las tasas de las aduanas; y en 1679 el establecimiento de una serie de convenios con las distintas colonias de mercaderes con derechos específicos para cada una que les eran favorables. Además, en 1679 y en 1688 se ratificó el derecho de Cádiz al embarco de hasta un tercio de frutos y ropas en las flotas, que disfrutaba desde 1597 (incluso desde 1507) . Una $^{4}$ disposición del 4 de julio de 1680 establecía el arribo y descarga de las flotas de Indias en el puerto de Cádiz, en la zona de Puntales. Hasta el propio José de Veitia Linaje denunciaba los «excesos» cometidos, tanto en cantidad de buque como en

Brest, Université de Bretagne Occidentale, 1996, pp. 149-160; y en: Crespo Solana, A.: «Cádiz y el comercio de las Indias: un paradigma del transnacionalismo económico y social (siglos XVI-XVIII)», e-Spania. Revue interdisciplinaire d'études hispaniques médiévales et modernes, 25, 2016, Publicado el 1 de octubre 2016, consultado el 1 de noviembre de 2016, URL: http://espania.revues.org.26016; DOI: 10.4000/e-spania.26016.

2. Narrado por GIRARD, A.: La rivalidad comercial y marítima entre Sevilla y Cádiz hasta finales del siglo XVIII. Sevilla, Renacimiento, 2006, pp. 92-114.

3. Por ejemplo, en un ya antiguo artículo de Barea Ferrer, J. L.: «La importancia de Cádiz a fines del siglo XVII: el arriendo de las aduanas», pp. 131-137, donde examina un interesante manuscrito de la Biblioteca Nacional de España [en adelante BNE], mss. 9400, sobre este asunto: «Discurso sobre si convenía dar en arrendamiento las aduanas de Cádiz a los comerciantes que querían arrendar igualmente otras de varios puertos marítimos».

4. Una breve aunque pormenorizada introducción histórica en: Bustos Rodríguez, M.: Cádiz en el sistema atlántico. La ciudad, sus comerciantes y la actividad mercantil (1650-1830). Madrid, Sílex, 2005, pp. 48-51. Martínez Shaw, C.: «El tercio de frutos de la flota de Indias en el siglo XviII», pp. 201-211. [en adelante Archivo General de Indias AGI], Contratación, 5093. 
calidad de géneros con los que los cargadores de Cádiz se aprovecharon con el fin de extender su privilegio de puerto de arribadas.

Es de sobra conocido, por la interesante bibliografía al respecto ${ }^{6}$, que este proceso no se dio por finalizado con la creación en Cádiz de una Casa de la Contratación unida a la Intendencia de marina en 1717; sino en el lapsus de tiempo, lleno de enigmáticos tiras y aflojas, que tuvieron lugar en la Corte de Madrid ante el Consejo de Estado y ante el Consejo de Indias, entre 1723 y 1725. En 1723 había fallecido el principal valedor del traslado de los tribunales, el almirante Andrés Matías de Pes y Malzárraga, quien tras una carrera como marino desarrolló una importante labor estadista. Su nombramiento como presidente del Consejo de Indias en 1717 supuso su enfrentamiento con el cardenal Alberoni para lograr el traslado de la Contratación a Sevilla. No mucho más se sabe de su actuación aparte de lo que Adolfo de Castro describe en su detallada y apologética biografía ${ }^{7}$, o la información que aparece en la correspondencia entre Pes y Patiño en 1722 poco antes de su muerte cuando le pide a su protegido que su deseo principal es volver a estudiar el informe de Manuel García de Bustamante del año de $1701^{8}$. Este memorial propiciaba en realidad la conversión de la Bahía de Cádiz en la sede de una especie de «compañía Armada» (sic) «por cuya mano corriese puntualmente el tráfico y contratación de la América» ${ }^{9}$. No obstante, es conocido el afán de Pes de proteger a José Patiño y Rosales, y de colocarlo en los puestos claves para llevar a cabo acciones concretas y determinantes en la reorganización naval y comercial. Andrés de Pes se justificaba en el Consejo diciendo que procedía al traslado de los tribunales porque era lógico que estos

tribunales se establecieron y deben subsistir en el puerto donde salen y entran las Armadas de Indias, tanto por lo conveniente que es al mayor servicio de S.M. cuando por el universal alivio que se sigue a los comerciantes que en ambos juzgados

5. Muro Orejón, A.: Cedulario Americano del siglo XviII, tomo II. Sevilla, 1969, pp. 30 y ss.; Veitia Linaje, J. de: Norte de la Contratación de las Indias Occidentales (Sevilla: Imprenta de Juan Francisco de Blas, 1672). Edición facsímil, Madrid: Instituto de Estudios Fiscales, 1981, Estudio preliminar de Francisco de Solano, p. 191.

6. Girard, A.: La rivalidad comercial; y especialmente Ravina Martín, M.: El pleito Cádiz-Sevilla por la Casa de la Contratación. El Memorial de Francisco Manuel de Herrera, Cádiz: Diputación Provincial, 1984.

7. Castro, A. de: Vida del Almirante Don Andrés de Pes, ministro de Marina. Cádiz, Imprenta de la Revista Médica, 1879.

8. AGI, Arribadas 192. Carta de Andrés de Pes a José Patiño, 1722. Citado en Crespo Solana, A.: La Casa de la Contratación, p. 109.

9. AGI, Indiferente General, 2046 A. Memorial de Manuel García de Bustamente. Citado en Crespo Solana, A.: La Casa de la Contratación, p. 111. 
tienen dependencias, pues con esta dependencia se les escusa el perjuicio que motiva la dilación de tener que pasar a Sevilla que dista 10 y 8 leguas de donde dejan sus navíos y los gastos de un viaje y demora en el litigio ${ }^{10}$.

Andrés de Pes aparece como un valedor de los intereses mercantiles, pero también señala cómo en las demás potencias marítimas los tribunales de comercio están siempre situados allí donde se organizan las flotas y armadas, pues es natural redirigir beneficios del comercio a la industria naval. Como hombre de mar experto en densas batallas marítima, Pes es un estadista práctico y preocupado por mercaderes y barcos, el capital social de la carrera de Indias. La sombra de la influencia francesa aparece en su discurso; Pes pone a Marsella y Sant Maló como ejemplos de ciudades comerciales con tribunales e industria naval, pero también a Génova y a «otras repúblicas» donde la construcción naval y lo comercial eran parte intrínseca del desarrollo portuario y, por ende, del de la nación ${ }^{11}$.

Solo ante el peligro, a la muerte de su mentor, José Patiño tuvo que demostrar en 1723 , con un bien organizado y técnico alegato, la realidad de una zona geográfica que reunía las características para la construcción y formación de las armadas y flotas: la seguridad de la bahía abierta, pero a la vez paradójicamente cerrada, y la existencia de unos careneros naturales, los caños de la Carraca y Trocadero. Así como José Patiño afirmaba que esta bahía:

no tiene parangón en otra parte de Europa y que son envidiadas de cualquiera nacional e inteligente, las circunstancias de su seguridad y carenero en los caños que se extienden tierra adentro hasta el Puente Zuazo de forma que viene a tener las dos estimables calidades que rara vez se junta en una provincia de una bahía abierta para la facilidad de su entrada, y salida de puerto cerrado en las estrecheces de sus caños, en el resguardo de sus castillos o fuertes y en el abrigo de los vientos ${ }^{12}$.

Poco a poco, el discurso de Patiño convierte el plan de revitalización comercial y naval en un anteproyecto de industria nacional de construcción de barcos que debía centrarse geográficamente en las áreas vasco-cántabras (de ahí la posterior intervención de Antonio de Gaztañeta) y en Andalucía. En Cádiz, el aprovechamiento de tan singular geografía en el doble sistema (privado e institucional) que definía el comercio español de Indias venía dado por la emergencia de crear una

10. "Informe que el 8 de marzo de 1720 hizo el Sr. Don Andrés de Pes, tocante a los motivos que hubo para que en el año de 1717 se hiciese pasar de Sevilla a Cádiz la Casa de la Contratación y el Consulado", Recopilación de diferentes resoluciones, Madrid, 1722. Citado en: Castro, A. de: Vida del Almirante, p. 38.

11. Castro, A. de: Vida del Almirante, p. 39.

12. AGI, Arribadas 10, Voto de José Patiño, 1723. 
ANA CRESPO SOLANA

LA INTENDENCIA DE MARINA Y EL «GOBIERNO DE LA CONTRATACION»: EL SUEÑO NAVAL DE JOSÉ PATIÑO Y ROSALES (1717-1736)

armada centralizada, creada en 1704 ante la conciencia de que había que defender el comercio y el imperio a los dos lados de los mares con una buena base legislativa y que sustituyera al antiguo cargo de Almirante Mayor de Castilla. Este último se había convertido en un nombramiento político-militar hereditario que había perdido sus responsabilidades navales ante una más que fragmentada conjunción de armadas y flotas que no tenían un liderazgo común ${ }^{13}$. Con la Real Cédula de febrero de 1714 se mandó unificar todas las escuadras y flotas existentes. Esto se reafirmó en el plano legal en junio de 1717 con la promulgación de unas Ordenanzas para la Armada y la instalación en Cádiz de la Intendencia General de Marina ${ }^{14}$. Pero los años finales del pleito por el traslado se vieron emplazados en una serie de avatares políticos. El control del ministro Juan Bautista de Orendáin sobre el Consejo de Indias a la muerte de Andrés de Pes (aunque su sucesor fue en realidad Baltazar de Zuñiga, marqués de Valero) hizo que se dictaminara a favor del regreso de los tribunales a Sevilla incluyendo la restitución de los mismos ministros que lo habían compuesto anteriormente y cuyo pago de salarios estaba pendiente. Pero una nueva coyuntura favorable en 1725 auspiciada por la llegada a la Corte del Barón de Ripperdá y las actuaciones de Francisco Manuel de Herrera lograron que la Casa de la Contratación se quedase en Cádiz junto a la Intendencia de Marina (de hecho el presidente de la casa era ahora presidente-intendente) ${ }^{15}$. Hasta el propio Cabildo gaditano agradeció a estos últimos que lograran la anulación de tal decreto de restitución a Sevilla ${ }^{16}$. La unión del comercio y la centralización

13. El almirantazgo dividido entre los almirantes de Castilla, Granada e Indias, tenían la potestad para las armadas, pero sus evoluciones fueron muy irregulares y las competencias generales fueron variando o pasando a otros cargos creados, como el del capitán general de la Mar (1517). La conexión con esta situación precedente está poco estudiada salvo en: CALDERÓN Ortega, J. M.: El Almirantazgo de Castilla: Historia de una institución conflictiva (1250-1560). Madrid. 2003; y Ceballos-Escalera y Gila, A.: El Almirantazgo General de España e Indias en la Edad Moderna. Madrid, Real Academia de la Mar, 2012.

14. Hay un excelente estado de la cuestión sobre la Armada o marina española del siglo XVIII en Baudot Monroy, M.: La defensa del Imperio. Julián de Arriaga en la Armada (1700-1754). Murcia, Ministerio de Defensa, Universidad de Murcia, 2012, pp. 42-95; Crespo SolanA, A.: La Casa de la Contratación y la Intendencia General de Marina en Cádiz (1717-1730). Cádiz, Universidad de Cádiz, 1996.

15. AGI, Indiferente General, 2039, Decreto de restitución firmado por el ministro Orendain, 21 de septiembre de 1725; AGI, Indiferente General, 2021. Copia de Carta de Ripperdá a Francisco de Varas y Valdés notificando la decisión de que los tribunales no debían regresar a Sevilla, Madrid, 31 de diciembre de 1725. Ravina Martín, M.: El pleito, pp. 77 y ss.; Crespo Solana, A.: La Casa de la Contratación, pp. 11 y ss.

16. Archivo Histórico Municipal de Cádiz [en adelante AHMC], libro de Actas Capitulares, tomo 81 (año 1725), pp. 511-539. Citado en Crespo Solana, A.: La Casa de la Contratación, p. 126. 
de la armada por la «vía reservada» era ahora la prioridad en el marco institucional y militar internacional; y lo era también para los propios intereses económicos de la Monarquía borbónica conocedora de que era más necesario que nunca formar parte del «lobby» gaditano integrado por compradores y vendedores ilegales de plata, así como por la importancia de la particularidad geográfica y logística de la bahía para la buena organización de las armadas de guerra y buques mercantes. Cádiz se había convertido en una sede socialmente aceptada de mercaderes entre los cuales aquellos más poderosos monopolizaban un mercado negro de metales, coordinado por extranjeros, la mayor parte transeúntes, que se dedicaban a comprar y a vender para hacerse con el metal. La mayor parte de ellos estaban emparentados entre $\mathrm{si}^{17}$. La Corona era consciente de que tenía que participar en este negocio y redirigir sus beneficios a convertir la bahía en un centro naval y de almacenamiento de madera y pertrechos para las armadas y flotas. Esto fue lo que sucedió a partir de ese momento, y más que un sueño de reactivación del comercio colonial sería a la larga un plan exitoso de industria naval.

\section{VisioneS COMPARADAS Y MODELOS DE SEDES NAVALES}

La historiografía más novedosa ha señalado cómo las actuaciones de la Intendencia de Marina (aunque esta algo menos valorada en los estudios existentes), y las etapas posteriores hasta concluir con la Instrucción General de mayo de 1723 (u Ordenanza de arsenales), y las Ordenanzas de Montes de enero de 1748 (extrañamente tardía en el devenir de los acontecimientos) significaron el despliegue de una concatenación de actividades portuarias que depositaba la industria naval en una política de arsenales, que no de astilleros solamente, bien estructurados y en donde con el paso del siglo se llegaron a realizar experimentos avanzados de ingeniería naval. Los arsenales se convirtieron en el eje de la marina, pues no solo era importante la construcción del navío en sí, sino el mantenimiento, carenado y reposición de piezas o arboladuras en su momento preciso cuando el navío debía partir en comisión de servicio ${ }^{18}$.

17. Crespo Solana, A.: «Confianza, cooperación y competencia en los mercaderes europeos. Mecanismos sociales en los documentos sobre pleitos entre mercaderes en Cádiz en el siglo XViII", en Vila Vilar, E. y Lacueva Muñoz, J. J. (coords.): Mirando las dos orillas: intercambios mercantiles sociales y culturales entre Andalucía y América. Sevilla: Fundación Buenas Letras, 2012, pp. 209-227.

18. Díaz Ordóñez, M.: Amarrados al negocio. Reformismo borbónico y suministro de jarcia para la Armada Real (1675-1751). Madrid, Ministerio de Defensa, 2009; MARTínez GonZÁlez, A. J.: «La elaboración de la Ordenanza de Montes de Marina, de 31 de enero de 1748, base de la política oceánica de la monarquía española durante el siglo xviII», Anuario de Estudios Americanos, 71:2, 2014, pp. 571-602. 
¿Cómo afectaron estas reformas a la organización de las flotas y su construcción en tiempo real? ¿Qué relación tenía esto en la práctica con el cambio del paradigma del modelo de Armada en España? Los años que se suceden entre las ordenanzas y leyes de 1717 y el final de la década de 1720 son aún confusos, a pesar de la abundante bibliografía que ofrece una gran cantidad de datos concatenados. No obstante, se han identificado varias etapas en lo que a mejora tecnológica se refiere, propiciada por la mejor organización administrativa y el avituallamiento de capital y recursos ${ }^{19}$. Estos años, sin embargo, constituyen el inicio del despegue de una armada que, aunque conoció éxitos y fracasos en la mar debido a desatentadas ambiciones de política internacional (no se olvide la derrota de la escuadra al mando de José Antonio de Gaztañeta en Cabo Passaro en 1718), contribuyó parcialmente a la recuperación comercial. Esta última, empero, ligada ya a unas nuevas circunstancias político-económicas en las relaciones de España con América $\mathrm{y}$ en las que, también a pesar de repetidos litigios contra los jenízaros, las redes de mercaderes extranjeras formaban parte intrínseca. A comienzos de la nueva década Gaztañeta escribió su memorial menos conocido, y que envío al Marqués de Grimaldo en febrero de 1723. Su ya demostrada sabiduría como constructor de barcos en su Arte de fabricar Reales (1687); o en su Proporción de las medidas arregladas a la construcción de un bajel de guerra de setenta codos de quilla (1712); hizo que en 1721, tras ser ascendido a teniente general, se promulgase una Real Cédula por la que se debían observar en la península y en ultramar sus reglas para la construcción de bajeles. Un memorial manuscrito de Gaztañeta firmado en Guarnizo en 1723 describe la detallada operación de la construcción de 32 bajeles de guerra durante cuatro años en los astilleros de Cádiz. Así se cumplía además el deseo real de establecer astilleros en Vizcaya y en Andalucía como base principal del programa de reformas de la marina ${ }^{20}$.

Pero este sueño de unión del comercio y la armada relacionada con la construcción naval solo puede entenderse en el análisis comparado internacional. Lo cierto es que, aunque la corona española careció de una auténtica marina propia, estamos de acuerdo con Ceballos-Escalera en que existió una estrategia naval hispánica con armadas y flotas que estaban estructuradas pero no centralizadas ${ }^{21}$. La falta de centralización hacía casi inviable, y a la larga un fracaso, la garantía de galeones y buques de guerra (generalmente expropiadas al sector privado en

19. Explicada de forma excelente en: García-Torralba Pérez, E.: Navíos de la Real Armada 1700-1860. Madrid, 2016.

20. Archivo Histórico Nacional [en adelante AHN], Estado, 2938, Guarnizo, 14 de febrero de 1723, Manuscrito de José Antonio de Gaztañeta al marqués de Grimaldo.

21. Ceballos-Escalera y Gila, A.: El Almirantazgo General, p. 40. 
comisiones de servicio) en la organización de expediciones, en muchos casos de naturaleza ofensiva más que defensiva. Se organizaban por el sistema de asientos para la construcción y apresto, es decir, también esto y el avituallamiento de recursos, incluida la madera, recaía en el sector privado, contratando buques y flotas con armadores nacionales y extranjeros. Se organizaba también con escuadras independientes en cada zona, razón de la existencia de distintas armadas entre las que estaban las Armadas del Océano y de la Guarda de la Carrera de Indias. Entre 1604 y 1643 se habían dado varios intentos de unificación y centralización pero en 1624 la Junta de Almirantazgo enviaba veedores a los puertos del reino para que el producto de sus recaudaciones (multas al comercio y al contrabando generalmente) se destinase a fabricar y armar galeones ${ }^{22}$. La Historia naval española está llena de casos semejantes desde la «Invencible» a Trafalgar. Es decir, la Armada española, aunque existía antes de 1704, era tan fragmentada y compuesta como el propio imperio al que representaba. El hecho de que otras naciones mercantilistas y marítimas se adelantaran a España a la hora de crear una armada estatal ha llevado en algunas ocasiones a plantearse la idea de modelos, como el holandés, el inglés o el francés. Geoffrey Parker afirmaba que el modelo inglés se basaba en la tenencia de una armada en tiempos de paz $^{23}$. Lo cierto es que estos «modelos» se basaban en la organización de arsenales y astilleros en ciudades portuarias claves, donde los barcos se sometían a mantenimiento, carenado e hibernación, priorizándose no solo la construcción en sí misma. Las ciudades portuarias atlánticas en aquella época presentaban un sistema similar con conexiones entre ellas que las hacia aglutinar una serie de factores relacionados con su naturaleza de almacén y centros para la re-exportación. En general eran siempre también áreas de arsenales y careneros, por no decir astilleros especializados. En esta jerarquía portuaria Cádiz se había ganado una posición primordial por su situación estratégica ${ }^{24}$. Solo en 1737, a la muerte de José Patiño, Felipe V volvió a restaurar el Almirantazgo con otras características y fijadas en las Ordenanzas de la Armada del Infante Almirante que restablecieron su jurisdicción ${ }^{25}$. Hasta la llegada del Marqués de la Ensenada no se conocerá un nuevo auge en la legislación y la organización naval siguiendo las líneas iniciadas por Patiño como intendente de marina en Cádiz. Pero ¿cómo

22. Quizás para la época de los Austrias, la mejor síntesis realizada recientemente sobre la marina sea: O’Donnell y DuQue de Estrada, H. (coord.): Edad Moderna I. Ultramar y la Marina, en Historia Militar de España. Madrid, Ministerio de Defensa, 2013.

23. Parker, G.: «Por qué triunfó el asalto a Cádiz en 1596?», en Bustos Rodríguez, M. (dir.): El Asalto anglo-holandés a Cádiz en 1596 y su contexto internacional, Cádiz, Universidad de Cádiz, Ayuntamiento de Cádiz, 1997, pp. 93-124.

24. Crespo Solana, A.: «Cádiz y el comercio de Indias», op. cit.

25. Ceballos-Escalera y Gila, A.: El Almirantazgo General, p. 13. 
pueden analizarse los logros de este período entre comienzos del siglo XVIII y el final de esta década de 1730 ?

Imperios marítimos comerciales y construcción naval han estado presentes en la forja de la imagen histórica de la evolución y formación de los poderes estatales y sus instituciones durante el siglo xviri. Para el caso inglés, por ejemplo, la expansión comercial ha sido definida historiográficamente como «an economic act perfomed within an essentially Ricardian framework, in which overseas trade was assumed to be international» ${ }^{26}$. La imagen de una nación marítima se veía reflejada en las guerras que sostenía; y el comercio, unido a la sostenibilidad de la navegación, constituían sinónimos de seguridad nacional. Esta idea, que puede resultar anacrónica si se analiza en el complejo escenario de la competencia colonial, ya figuraba en algunos escritos político-económicos, como en la obra An Historical and Chronological Deduction of the Origin of Commerce de Adam Anderson, editada en $1764^{27}$. En este contexto, España no era una excepción, como tampoco lo había sido antes. Al igual que lo hicieron Inglaterra, Portugal, Francia o la propia Holanda, España constituyó su particular sistema organizativo de control del comercio marítimo, navegación de flotas y construcción naval. En parte por razones de Estado, pero también por cuestiones de negocios privados desde los tiempos de los Reyes Católicos, este sistema se vio sometido a un cuerpo legislativo que afectó a la logística de las flotas de Indias y la defensa político-militar del imperio, aunque no siempre se reflejó en una evolución paralela, la cual atendió más al propio desarrollo interno colonial y a las distintas confluencias que tuvieron lugar en la propia forma de cómo se organizaban los negocios de la Carrera de Indias. Aunque desde el siglo XVi hubo quien clamaba por la libertad comercial, lo cierto es que muchos se lucraban con el monopolio teórico y con las excepciones legales. Durante toda la Edad Moderna, estas cuestiones eran la base de la propia acción o efectividad de los sistemas marítimos y, sobre todo, de la seguridad nacional. La idea de monopolio y centralización son ideas ya esgrimidas en los clásicos trabajos sobre las

26. Ormrod, D.: The rise of Commercial Empires. England and the Netherlands in the Age of Mercantilism, 1650-1770. Cambridge, Cambridge University Press, 2003.

27. ANDERSON, A.: An historical and chronological deduction of the origin of commerce: from the earliest accounts. Containing a history of the great commercial interests of the British Empire. To which is prefixed an introduction, exhibiting a view of the ancient and modern state of Europe; of the importance of our colonies; and of the commerce, shipping, manufactures, fisheries, Ec., of Great-Britain and Ireland; and their influence on the landed interest. With an appendix, containing the modern politico-commercial geography of the several countries of Europe. Carefully rev., cor. and continued to the present time..., Impr. John Walker, 1787. 
ANA CRESPO SOLANA

LA INTENDENCIA DE MARINA Y EL «GOBIERNO DE LA CONTRATACION»: EL SUEÑO NAVAL DE JOSÉ PATIÑO Y ROSALES (1717-1736)

rutas comerciales atlánticas ${ }^{28}$. No se cambió durante siglos, especialmente debido a la fuerte oposición de los principales beneficiarios del sistema comercial, las aristocracias castellano-sevillanas.

Pero con el final de la guerra de Sucesión a la corona española en 1713 todo apuntaba a una nueva política que en gran medida se esforzó por fortalecer el antiguo sistema de flotas y galeones con sede de organización y arribadas en un solo puerto $^{29}$. Para entender esta reorganización del comercio colonial, más que de reforma del mismo, hay que comprehender el marco de los problemas que la guerra marítima trajo al comercio español entre 1690 y 1713. Aún en 1699 un memorial del capitán sevillano Bartolomé Antonio Garrote a la Junta de Comercio definía cuáles eran exactamente los problemas de las flotas. Este memorial es curioso por reclamar que con el objeto de mantener la regularidad de las flotas solo se debía hacer «hoy mismo lo que se ejecutaba desde el año de 1580 hasta el de 1680 que es que los galeones y flotas vayan continuados todos los años con las mismas permisiones que dichas flotas de Tierra Firme y Nueva España llevan haciendo pues es el modo más breve y más fácil de quitar de aquellas cosas el comercio de las Naciones y el remedio único de nuestra España» ${ }^{30}$. En parte, la tardanza de las flotas en llegar y la alta demanda superior a la oferta que había producido en América un crecimiento del comercio interregional, eran la base del problema. «La falta de nuestro comercio por la naturaleza de las Armadas hace que lo que había de ser útil para España lo sea de las Naciones», decía Garrote ${ }^{31}$; y continuaba:

Estos viajes, señor, se expedían con la facilidad, felicidad y brevedad que tengo manifestado a VM pues eran de seis a ocho meses y el más dilatado no pasaba de nueve. La frecuencia de viajes, señor, es el único y total medio de que la Carrera de Indias no se pierda, porque se crían cautos, se despiertan soldados, se adiestran pilotos y oficiales de mar, se enseñan astilleros, se hacen inteligentes marineros, se educan hombres de mar para las navegaciones, se enriquecen los comerciantes vasallos de $\mathrm{Vm}$, se conducen los sueldos de sus ministros de VM, se mantienen

28. Vázquez de Prada, V.: «Las rutas comerciales entre España y América en el siglo XVIII», Anuario de Estudios Americanos, XXV, 1968, pp. 197-241.

29. García-Baquero GonzÁlez, A.: «Comercio colonial y reformismo Borbónico: de la reactivación a la quiebra del sistema comercial imperial», Chronica Nova, 22, 1995, pp. 105-140; Walker, G. J.: Política española y comercio colonial, 1700-1789. Barcelona, Ariel, 1979.

30. Manifiesto al Rey y al Consejo de Indias, del Capitán de Mar y Guerra, Bartolomé Antonio Garrote, en que demuestra que las Armadas y flotas de Nueva España y Tierra Firme han salido de estos reinos para América todos los años desde 1580 a 1699, BNE, mss. 12633, fols. 192-214. Este documento está incluido en la obra de ANTúneZ y ACEvedo, R.: Memorias bistóricas sobre la legislación y gobierno del comercio de los españoles con sus colonias en las Indias Occidentales. Madrid, Imprenta de Sancha, 1797.

31. Manifiesto al Rey..., p. 194. 
ANA CRESPO SOLANA

LA INTENDENCIA DE MARINA Y EL «GOBIERNO DE LA CONTRATACION»: EL SUEÑO NAVAL DE JOSÉ PATIÑO Y ROSALES (1717-1736)

y sustentan los ministros de la Real Casa de la Contratación de esta ciudad, que está pereciendo, el Real Colegio y Seminario de los Niños de San Telmo, (...) y enseñar los niños naturales de estos reinos para que no entren extraños a gobernar las embarcaciones, como sucedía pocos años ha ${ }^{32}$.

En las décadas de 1680 y 1690 dos problemas parecían tener paralelismo con el advenimiento del final de la rama española de la dinastía de los Austrias. Por un lado estaba la supuesta debilidad de la conexión mediante las flotas que surcaban el Mar Hispánico («Hispanische See»), tal como los mercaderes del norte de Europa llamaban al océano que se extendía más allá del canal de La Mancha ${ }^{33}$, y que cruzaba el Atlántico a través del paralelogramo «lying between the ebb of the trade wind and the flow from the mid-way latitude» ${ }^{34}$. En segundo lugar, era evidente la vulnerabilidad de los puertos americanos continuamente asediados por las armadas de otros países competidores en la carrera atlántica. Ello produjo que varias áreas geográficas americanas, como el Golfo Caribe y algunas zonas más aisladas en América del Sur, formaran parte aún más de la estrategia defensiva y militar de la Casa de Austria durante el siglo xviI, como bien ha indicado Rafal Reichert, especialmente orientados a debilitar la penetración extranjera ${ }^{35}$.

Esto se acució con el gran problema por antonomasia, a comienzos del siglo XVIII: la guerra marítima atlántica que, como consecuencia de la crisis sucesoria, la guerra de los aliados contra la pretensión de Francia al trono español y los continuos asedios de aquellos al espectro geográfico-marítimo del imperio español puso de relieve la vulnerabilidad del sistema comercial y las flotas que lo sustentaban. En parte puede decirse que la crisis del comercio de Indias es paralela a la crisis sucesoria al trono de España, ya que se identificarían ambos problemas como

32. Idem, p. 199.

33. Pietschmann, H.: «Un testimonio alemán desconocido sobre el comercio y la navegación en el Atlántico: la curiosa descripción de Friedrich Martens de una navegación de Hamburgo a Cádiz en 1671-72», en Armillas Vicente, J. A. (ed.): Actas del VII Congreso Internacional de Historia de América. Ponencias y Comunicaciones. Zaragoza, 2 al 6 de julio de 1996. Zaragoza, 1998, pp. 1763-1796; citado en: Pietschmann, H.: «Imperio y comercio en la formación del Atlántico español», en Oliva Melgar, J. M. y Lobato, I. (eds.): El sistema comercial español en la economía mundial (siglos XVII-XVIII). Homenaje a Jesús Aguado de los Reyes. Huelva, Universidad de Huelva, 2013, pp. 71-95.

34. Según la descripción que en su día hiciera Pierre Chaunu, recogido en Crespo Solana, A.: «The Wider World: Spatial Expansión and Integration in the Hispanic Atlantic, 16th to 18th Centuries», en Crespo Solana, A. (ed.): Spatio-Temporal Narratives. Historical GIS and the Study of Global Trading Networks (1500-1800). Londres, Cambridge Scholar Publishing, 2014, pp. 1-45.

35. Reichert, R. B.: «El Caribe Centroamericano en la estrategia defensivo-militar de la Casa de los Austrias, siglos Xvi y XvII», Caribbean Studies, 44:1-2, 2016, pp. 111-139. 
algo intrínseco a la pérdida de prestigio de la monarquía en Europa, asediada en su comercio y en la lucha interna por el control político ${ }^{36}$. ¿Qué paso en aquel año fatídico de 1680 que refiere el memorial del capitán Antonio Garrote? En ese año se produce un evento interesante para el futuro del comercio de Indias, la Junta de comercio donde Josep de Veitia Linaje trabajaba en la confección de su Norte de la Contratación; una Real Junta General de Comercio, creada en 1679, constituida por afectos a la causa de Don Juan José de Austria, quien era también almirante de las Indias ${ }^{37}$, y por el Duque de Medinaceli que tenía como objetivo, entre otras cuestiones, el fomento de las actividades fabriles, incluidas las industrias navales. Era un momento difícil para la monarquía Hispánica por el problema de la crisis sucesoria que se avecinaba y que ya había puesto a aliados $\mathrm{y}$ enemigos en posición de reclamar intereses en el comercio español con presencia física incluso en importantes ciudades portuarias de la Monarquía. Todos o casi todos los puertos españoles y americanos relacionados con la ruta oceánica de la Carrera de Indias se vieron amenazados e incluso atacados por las flotas anglo-holandesas; y la Armada francesa, lejos de proteger esos puertos y a las mismas flotas (supuestamente aquello por lo que eran aliados), lo que hizo fue aprovechar su cercanía y acceso a ellas para desorganizarlas y vilipendiarlas. En este escenario, 1702 es un año determinante para Cádiz, debido al asedio que la flota aliada Austracista hizo de la ciudad y la postura que los mercaderes de Cádiz tuvieron durante la contienda, que indudablemente pudo influir en las posteriores decisiones Borbónicas ${ }^{38}$.

La organización de las flotas de Indias ha sido estudiada sobre todo desde el punto de vista institucional y de su organización y despacho a través de la Casa de la Contratación. Este esquema de análisis se ha ido repitiendo en la historiografía tanto para la época de la residencia de estos tribunales en Sevilla, desde

36. Ya hice un análisis de esta visión en Crespo Solana, A.: «A Change of Ideology in Imperial Spain? Spanish Comercial Policy with America and the Change of Dynasty (16481740)», en Onnekink, D. y Rommelse, G. (eds.): Ideology and Foreign Policy in Early Modern Europe (1650-1750). Londres, Ashgate, 2011, pp. 215-243.

37. Don Juan José de Austria había sido nombrado por Felipe IV encargado del «gobierno general de mis armas marítimas», que era Almirante General propietario de la Armada del Mar Océano y General de Artillería. AHN, Estado, 1414 (agradezco a Koldo Trápaga Monchet esta valiosa información).

38. Manuel Danio Granados, Diario puntual de todo lo sucedido desde el día 23 de agosto de 1702, en que dio vista a esta ciudad de Cádiz y Costas de Andaluzía, la armada naval enemiga de Inglaterra y Olanda, hasta el primero de octubre del mismo año en que se perdió..., Cádiz, Imprenta de Christoval de Requema, 1702. Biblioteca del Banco de España; Bustos RodríGuez, M.: «La ciudad de Cádiz y su contribución militar a la Guerra de Sucesión española, 1704-1705», Anales de la Universidad de Cádiz, 1, 1984, pp. 139-148. 
1503 como para el período gaditano, pero aún plantea preguntas como cuáles eran las atribuciones reales de los funcionarios en los puertos aledaños de arribadas y cómo se las ingeniaban para suplir la carestía de barcos ${ }^{39}$. Ya se ha indicado cómo a pesar de la centralización del puerto único con fines de control de la organización y de fiscalización del comercio, se hizo necesaria la proliferación de una serie de Juzgados de arribadas situados en algunos enclaves marítimos claves, como Sanlúcar de Barrameda y Cádiz. También desde 1529 otros puertos peninsulares habían sido habilitados para comerciar con América con la única obligatoriedad de que las arribadas de retornos se hicieran en Sevilla, aunque solo los dos anteriores podían sustituir a Sevilla como puerto de arribada, y se sabe que esta ley apenas se cumplía en la práctica ${ }^{40}$. El sostenimiento del comercio de Indias, ahora desde Cádiz, conoció una serie de reformas políticas que han sido muy estudiadas, aunque aún presentan ciertos claroscuros. Se enmarcan en un difícil período de reformas que acaecieron de forma interrumpida y difusa desde 1702. Las primeras reformas de Felipe V eran necesarias en todos los aspectos, aunque recibieron muchas oposiciones. El marqués de Uztáriz, en su «Discurso sobre el gobierno de Madrid» describía algunas de estas oposiciones como las que presentó Gregorio de Mella, veedor general de Cataluña, sobre las milicias de mar y guerra, y otros «expertos y entendidos ministros de la guerra (que) se opusieron a todo lo que pensaban era ideas de franceses y de otros ministros españoles llegados de Flandes (sic) ${ }^{41}$. No obstante, fue un ministro español, de origen gallego y nacido en la Milán ocupada por el ejército español donde su padre era Veedor intendente ${ }^{42}$. En realidad, si hay que destacar a un gran pionero en las reformas navales españolas, ese fue José Patiño, y sus supuestas influencias

39. SCHÄFer, E.: El Consejo Real y supremo de las Indias. Historia y organización del Consejo y de la Casa de la Contratación de las Indias, Madrid-León, Marcial Pons-Junta de Castilla y León, 2003, 2 vols.; Crespo Solana, La Casa de la Contratación, y especialmente el compendio de trabajos recogidos en: Acosta Rodríguez, A., González Rodríguez, A. y Vila VILAR, E. (coords.): La Casa de la Contratación y la navegación entre España y las Indias. Sevilla, Universidad de Sevilla, CSIC, Fundación El Monte, 2003.

40. Estos puertos eran: La Coruña, Bayona, Avilés, Laredo, Bilbao, San Sebastián, Cartagena y Málaga. Caballero Juárez, J. A.: El régimen jurídico de las armadas de la Carrera de Indias, siglos XVI y XVII, México, 2001. (Se puede consultar en Internet: http://www.bibliojuridica.org/ libros/libro.htm?l=163).

41. Marqués de Uztáriz, Discurso sobre el Gobierno de Madrid, BNE, mss. 7049. Informe del 23 de febrero de 1714 y memorial impreso de junio de 1716 sobre la nueva Planta de las tropas a imitación de las de Francia, pp. 6 y 7. Editado por Pere Molas Ribalta.

42. Pulido Bueno, I.: José Patiño. El inicio del gobierno político-económico ilustrado en España. Huelva, 1998; Pérez Fernández-Turégano, C.: Patiño y las reformas de la administración en el reinado de Felipe V. Madrid, Ministerio de Defensa, 2006. 
francesas podrían ser puestas en entredicho ${ }^{43}$. Patiño fue posteriormente mentor del Marqués de la Ensenada, quien aplicó a sus Ordenanzas la mayor parte de las prácticas de aprestos de flotas emprendidas por Patiño en la primera mitad del siglo. José Patiño aunó en su persona el control de la Casa de la Contratación y la Intendencia de Marina, en un intento de supervisar personalmente y en forma de «vía reservada» la fiscalización del comercio, la organización de las flotas y galeones y la inversión práctica en los careneros y los avituallamientos de las flotas. Mantuvo estos puestos, aunque de forma discontinua, entre $1717 \mathrm{y}$ 1726, cuando fue nombrado Secretario de Estado de Hacienda, Marina e Indias, puesto que ocupó hasta su muerte. En su biografía política destaca el impacto y las consecuencias sin precedentes que su labor tuvo en el diseño de la armada y en la logística de las flotas y galeones.

\section{LA InTENDENCiA de Marina COMO PARAdigma}

La llegada de Patiño al poder está relacionada con los problemas de José del Campillo con la Inquisición de Logroño, cuando fue acusado de tener en su casa libros prohibidos. Campillo, en su defensa, afirmó: «los libros consisten en diferentes cartas que tienen parte de la historia de Felipe IV y menor edad de Carlos II, los dos últimos luises de Francia y algunos otros príncipes; pero en medio de la licencia y no estar exceptuados, no los ha tocado sino el polvo después de que se prohibieron y lo supe que habrá seis meses» ${ }^{44}$. En su defensa, él mismo narra los antecedentes de esta Intendencia de marina. En 1715 Campillo había pasado a servir en Sevilla junto a D. Francisco de Ocío y Salazar, intendente general de Andalucía en aquel año, como paje, hasta que fue sustituido por José Patiño en 1717. Campillo se hizo marino entonces e intentó defenderse de las acusaciones de leer libros prohibidos y conversar con herejes en sus viajes de navegación. Campillo redactó una Inspección de las seis secretarías de Estado y calidades y circunstancias que deben incurrir en sus respectivos secretarios donde como secretario de Estado nombra a Patiño como buen ministro y gobernante

43. Aunque la familia Patiño desde el estado de Milán apoyaron la causa de Felipe V, sino más bien viene de una tradición de proyectistas españoles como José del Campillo, Miguel Zabala y Auñón, Argumosa Gándara (que fue yerno de Ripperdá, colaborador también de Patiño en el traslado de la Contratación), e incluso el propio Melchor de Macanaz y de Gerónimo de Uztáriz. Cfr. Pulido Bueno, I.: José Patiño, pp. 27 y ss.

44. Carta que escribió José Del Campillo y Cossío a D. Joseph Gerónimo de Mier, inquisidor de Logroño, sobre la causa que se le formó en materia de fe a dicho Campillo, escrita en 28 de julio de 1726, fols. 41-47, fol. 10. BNE, mss. 10849. Martínez Navas, I.: «El Tribunal del Santo Oficio de Logroño y Don José del Campillo y Cossío», Berceo, 140, 2001, pp. 275-292. 
que sabe controlar las materias de estado, comparándolo con el Cardenal Cisneros o con Antonio Pérez ${ }^{45}$. En esta obra Campillo describe la Secretaría de marina necesaria para acrecentar la cultura y aprendizaje del marino, pero resalta que debía tener a su cargo la recíproca inspección y manejo con las repúblicas inmediatas a costa de fomentar y conservar los montes para la tala de los árboles del respectivo diámetro para las fábricas de navíos; y, sobre todo, el general conocimiento e inspección de los alistamientos de marina para educar marineros hábiles, expertos y vigorosos, y surtirse así cultivar los oficios necesarios para la construcción de barcos «composturas de ellos y de sus respectivos pertrechos, para guardar nuestros mares, ampliar hasta lo posible el comercio y contener con tanto rigor como arregladas providencias el orgullo, arrogancia y perniciosas máximas de los enemigos comunes piratas y potencias marítimas» ${ }^{46}$.

Este breve antecedente en el pensamiento político y naval de José del Campillo es relevante para entender la actitud de Patiño y la naturaleza de la Intendencia de Cádiz. Sin embargo, la introducción del sistema de intendencias en España en 1711 tiene antecedentes ya en tiempos de Felipe IV, aunque se ha insistido mucho en el modelo francés, por las innovaciones que a partir de ahora afectaban a cuestiones amplias dentro de las demarcaciones provinciales. Al parecer fue el ministro Jan van Brouchoven, conde de Bergeyck, quien le dio su configuración definitiva en España otorgándole ese cariz de cuasi agentes de la ley subordinados solamente al rey y que entendían de justicia y finanzas ${ }^{47}$. El marqués de Monroy fue nombrado entonces Superintendente general del ejército con sede en Sevilla y debido a los problemas de las flotas en el puerto de Cádiz se encargó, también en 1711, a Francisco de Varas y Valdés, ministro del Tribunal de la Contratación de Sevilla, a que se trasladase a Cádiz con el objeto de supervisar los arribos de flotas. Aunque Francisco de Varas recibió el título de intendente de marina, dependía de la Superintendencia de Sevilla. Actuó como un juez privativo para el despacho de flotas y galeones y aunque sus delimitaciones estaban aún sin precisar, su labor fue de gran importancia sobre todo durante las ausencias de Patiño de Cádiz ${ }^{48}$.

45. "Inspección de las seis secretarías de Estado y calidades y circunstancias que deben incurrir en sus respectivos secretarios», BNE, mss. 10849.

46. "Inspección de las seis secretarías...", fol. 89.

47. Kamen, H.: «El establecimiento de los intendentes en la administración española», Hispania. Revista Española de Historia, 24, 1964, pp. 63-76; AbBad, F. y Ozanam, D.: Les Intendants espagnols du XVIIIe siécle. Madrid, 1992.

48. En realidad este puesto era parecido al antiguo juez de arribadas. La documentación se encuentra en AGI, Juzgado de Arribadas de Cádiz, generalmente citado como Arribadas. En este caso es el legajo número 3. 
Con el traslado del tribunal de la Contratación la creación de la Intendencia de Marina aunó las cuestiones fiscales y navales en un solo paquete de acciones solo controlados por una mano, la de Patiño, y en su ausencia por Francisco de Varas y Valdés. Es por este binomio de comercio y marina por lo que quizás lo más importante desde el punto de vista institucional fue la creación de esta Intendencia General. Fue, efectivamente, la única en ser «de marina» ${ }^{49}$, y debía encargarse del acopio de víveres y pertrechos, asientos de marinería, fábrica de jarcias, lonas, betunes y artillería, además de cuidar de la materia prima para la construcción y carenado: el corte y fomento de los bosques ${ }^{50}$. Aunque la organización del suministro de maderas para las flotas reales se remonta a la década de 1570, con el nombramiento de Cristóbal de Barros como superintendente de montes y plantíos para el área Cántabra, la existencia y proliferación de las superintendencias sufrieron también de una relativa fragmentación solo superada con la aparición de nuevas normativas para la administración forestal que, aunque recogía la experiencia de las distintas superintendencias, como indica Martínez González, se introdujeron aspectos técnicos nuevos, «la ampliación del radio de acción jurisdiccional a otras zonas peninsulares y más alejadas de la costa y ríos navegables, así como la presencia de nuevos agentes y estructuras de la Monarquía borbónica» ${ }^{51}$. En el caso de Andalucía esta reorganización se reflejó en la inclusión oficial de la Sierra de Segura y Cazorla en el programa de construcción naval y la experimentación con pinadas que eran transportadas por ríos en forma de balsa integrada por troncos. Este sistema fue ampliado en décadas posteriores y la zona se convertiría en una provincia del Departamento marítimo de Cádiz ${ }^{52}$.

El 28 de enero de 1717 se promulgó la Real Orden que nombraba a José Patiño Intendente General de Marina de España, un ministro, tal como decía la dicha Real Orden, «para el resguardo de mis dilatadas costas marítimas en el Océano y Mediterráneo» así como de regular las armadas, flotas y escuadras, un dictamen que

49. Авbad, F. y Ozanam, D.: Les intendants espagnols; Kamen, H.: «El establecimiento», pp. 368-395.

50. AGI, Arribadas, S29 y 267 A, Oficios y comunicaciones de la Intendencia general de Marina; Contratación, 5786, L. 2, fol. 15, Real Orden a José Patiño, 25 de agosto de 1721.

51. Martínez GonzÁlez, A. J.: Las superintendencias de Montes y plantios (1574-1748). Derecho y política forestal para las armadas en la Edad Moderna. Valencia, Tirant lo Blanch, 2015 , p. 542.

52. Hay información en: Araque Jiménez, E.: Los últimos pineros. El transporte fluvial de madera desde las sierras de Segura y Cazorla (1894-1950). Jaén, Universidad de Jaén, 2016, p. 13 y pp. 19-27. Cfr. también: TRIndAdE, A. R.: «Bourbon Naval Policy, Forestry and Timber Supply for Shipbuilding in Andalucia (1700-1759): Brief introductory research notes», en VAREla Gomes, R. (coord.): The Management of Iberian Forest Resources in the Early Modern Shipbuilding: History and Archaeology. Lisboa, IAP, 2015, pp. 57-65.

Ediciones Universidad de Salamanca / 요 Stud. his., H. ${ }^{a}$ mod., 39, n. 2 (2017), pp. 75-114 
ANA CRESPO SOLANA

LA INTENDENCIA DE MARINA Y EL «GOBIERNO DE LA CONTRATACION»: EL SUEÑO NAVAL DE JOSÉ PATIÑO Y ROSALES (1717-1736)

lleva implícito la centralización de la Armada ${ }^{53}$. La creación del cargo de Intendente de marina se hizo de forma unipersonal al mismo tiempo de la orden del traslado del tribunal de la Contratación el 8 de mayo de 1717, y firmada por el ministro Miguel Fernández Durán ${ }^{54}$. Ello llevaba aparejado una libertad sin precedentes para la toma de decisiones prácticas en relación a la «fábrica de bajeles, su carena y composición, provisión de víveres, compra de pertrechos, razón del consumo, cuenta y razón de la distribución de los caudales que se emplean en estos fines». También incluía la prerrogativa de pagar a la «gente de mar y guerra, así de armadas y escuadras como de navíos sueltos». El intendente debía vigilar el régimen y progreso de la construcción de barcos en aquellos parajes que fuesen los más adecuados, tanto para la industria como para el almacenamiento de maderas y otros recursos (como jarcia y lona), así como los almacenes relativos a géneros y pertrechos necesarios para su embarque. Tenía que garantizar que cuando los navíos de las Reales Armadas llegasen a cualquier puerto encontrasen todo lo necesario para el curso de su navegación. Con tal objeto el cargo de intendente tenía competencias de administración fiscal ${ }^{55}$. Así, esta intendencia supone un auténtico antecedente de un ministerio naval independiente a cargo de un competente oficial o secretario de Estado que entendiese en los asuntos de la marina en relación a las Indias y el comercio atlántico. España quedaría dividida en departamentos navales cada uno gobernado por un cuerpo de intendentes, comisarios y tesoreros. Se ocupaba también de las diferentes clases de oficiales y escuelas navales. Debería haber astilleros y fortificaciones en cada uno de los departamentos. Se materializó en 1726 con la creación de los Departamentos de Marina, afectando especialmente a la organización de la provisión de recursos forestales desde los montes de marina ${ }^{56}$. La creación de la Intendencia de marina

53. Saralegui y Medina, L.: Historia del cuerpo administrativo de la Armada. El Ferrol, 1867 , p. 64.

54. AGI, Contratación 5070 A. Real Decreto de 8 de mayo de 1717, Segovia. Fue ratificada el 12 de mayo por Andrés de Pes, gobernador del Consejo de Indias. Existen varias copias en AGI, Indiferente General, 542, libro 2; 2020 y 2039. Cfr. Crespo Solana, A.: La Casa de la Contratación, pp. 46 y ss.

55. Estas atribuciones están esparcidas en sucesivas ordenanzas y leyes: AGI, Indiferente General, 542, libro 2: «Ordenanzas generales para la formación de las Intendencias. Real Decreto firmado en San Lorenzo del Real por D. Miguel Fernández Durán, secretario del Despacho, 26 de julio de 1718 (Impreso); AGI, Libros Antiguos (siglo XVIII), 208. Ordenanzas del 4 de julio de 1718 para el establecimiento e instrucciones de intendentes, y para el tesorero general, pagadores y contadores de los ejércitos y provincias, Por Orden de S. M. impreso en 1735 por Juan de Aristía.

56. López Arandia, M. A.: «Maderas del rey. Aprovechamientos madereros en la provincia marítima de Segura de la Sierra», en Araque Jiménez, E. y Moya García, E. (coords.): Aprovechamientos madereros en los montes jiennenses (siglos XIII-XX). Jaén, 2012, pp. 13-78. 
también afectó así a la organización de los bosques. La Real orden de la creación de la Intendencia de marina incluía que el intendente:

debía tener cuidado de la conservación de los montes y plantíos cercanos a las costas destinados hasta ahora a este servicio, y la plantificación de los árboles, para que cuando sea menester se corten, o ya sea para construcción de bajeles, o ya para carenas, en cuya consecuencia deberá pedir y tomar desde luego individual noticia de todos los que se hallaren capaces de servir a estos fines, con distinción de los que hubiere en mis montes realengos o de particulares y sus distancias a los astilleros donde yo mandare construir las fábricas, con todo lo demás que mira a la mayor comodidad y beneficio en su conducción ${ }^{57}$.

La conservación de los bosques estuvo presente en el pensamiento político de Patiño y quizás influyó en las Ordenanzas para la cría, conservación, plantios $y$ cortatas de los montes, con especialidad los que están inmediatos a la mar y ríos navegables. Métodos y reglas que en esta materia deben seguir los intendentes de marina, establecidos en los tres Departamentos de Cádiz, Ferrol y Cartagena ${ }^{58}$. Estas normativas estaban también incluidas en las Ordenanzas de Marina de 1748 que también recogen, si no copian casi literalmente, las ideas de José Patiño, mentor del marqués de la Ensenada.

Patiño fue intendente y presidente de la Casa de la Contratación hasta 1718, cuando participó en la batalla de Mesina. Entre 1719 y 1721 el cargo se dividió entre Francisco de Varas y Valdés y Andrés Pérez Bracho, quien cayó en desgracia supuestamente por un caso de corrupción fiscal. Francisco de Varas y Valdés declararía años más tarde que él mismo colaboró en la organización de la expedición de Sicilia recibiendo en Cádiz navíos que para este fin venían de Vizcaya, Galicia y Cuatro Villas y como «no hallando en la Tesorería de Cádiz todo el caudal que V. M. dispuso fuese en dichos navíos, se vio el suplicante a buscar a su crédito, entre diferentes comerciantes, 135.500 pesos con lo que se pudo enterar lo dispuesto, sin que este adelantamiento le hubiese sido de costo alguno a la Real Hacienda, por haberlo conseguido sin intereses, como le sucedió en otras ocasiones ${ }^{59}$. Los navíos que pudieron salvarse de esta campaña regresaron al mando de Balthasar de Guevara. Este acontecimiento bélico provocó de nuevo el «rompimiento» con Inglaterra. Y a pesar de la gravedad del asunto, Varas y Valdés tuvo que afrontar el envío continuo de navíos a América además de organizar unas escoltas de naos de

57. AGI, LA (siglo XVIII) 208. Ordenanzas del 4 de julio de 1718.

58. Ordenanzas, impresas en Cartagena, 1788, por D. Pedro Ximénez, impresor de marina.

59. Francisco de Varas y Valdés, puesto a los pies de V. Magestad, dize: Que en todo el tiempo que ha tenido la honra de servir a V. Magestad, p. 28 et passim. 
guerra para la armada de Barlovento. Debido a la sobrecarga de trabajo Francisco de Varas suplicó al rey que nombrase a otra persona encargada de la marina y la Intendencia. El 1 de enero de 1719, se nombró a Andrés Pérez Bracho como intendente de marina y tropas, quedando Varas al cargo de lo tocante a Indias, Comercio, Islas Canarias y Contratación. Sin embargo, el 28 de junio de 1719, Andrés Pérez Bracho fue apartado del empleo de marina y el rey dictaminó que el empleo de intendente pasase de nuevo a Varas y Valdés en propiedad ${ }^{60}$.

De forma paralela existía un organismo en Sevilla, la Superintendencia, que implicaba otra contaduría con atribuciones fiscales duplicadas, y desde la cual se lanzaron quejas sobre la mala utilización de los reales derechos de Indias. Esto era debido a que entre 1721 y 1722 el intendente de marina lo era a su vez del ejército y de Andalucía, y confundió cajas que debían permanecer separadas ${ }^{61}$. El problema era la duplicación de instituciones para cobrar los derechos, existiendo la Contaduría de derechos reales de Indias y la Tesorería de marina. La duplicidad de funciones de las instituciones era un problema de la administración del estado moderno en España y se vio alterada considerablemente por el doblamiento de funciones entre la Casa de la Contratación e Intendencia en Cádiz y las oficinas de Sevilla. Además estaba el problema del pago de sueldos de los ministros anteriores, algo que aún continuaba pendiente en $1717^{62}$.

En 1721 Patiño volvió a recuperar el cargo unificado de intendente y presidente hasta que en 1725 nombró a Francisco de Varas y Valdés de nuevo, tras aclararse su situación personal acusado de participar en casos de corrupción. Francisco de Varas se había defendido en un memorial de 1721 donde narra cómo la CasaIntendencia se había convertido en una especie de doble organismo que tenía, a todas luces, prerrogativas duplicadas, haciendo así a veces caótico el control fiscal del comercio y la aplicación de los fondos procedentes del mismo a las necesidades de la organización y apresto de armadas ${ }^{63}$. Hay que señalar que Francisco de Varas presentó un voto contrario a la actuación de los tribunales de la Contratación en

60. Idem, p. $29 \mathrm{v}$.

61. Quejas por Francisco de los Ríos Gil de Córdoba, Juan de Tovar y Antonio de Sotomayor. Ríos Gil de Córdoba había ejercido a veces como juez de arribadas, y estaban muy relacionados con el Consulado. AHN Estado 3214. Agradezco a Anne Dubet que me proporcionara este documento.

62. AGI, Arribadas 3.

63. Francisco de Varas y Valdés, puesto a los pies de V. Magestad, dize: Que en todo el tiempo que ha tenido la honra de servir a V. Magestad, no se avra visto instancia suya ... pero ya se ve necessitado a romper el silencio ... experimentando que la malicia ... intenta perjudicarle ... y no siendo dable tenga presente todos los encargos ... expresara solo aquellos de que pueda hazer memoria; s.i; s.n; s.a. Museo Naval de Madrid [en adelante MN]. 
Cádiz, aliado con los adalides de Sevilla, especialmente con Manuel López Pintado, el marqués de Miraval y Uztáriz, cuyos testimonios estudió Ravina Martín ${ }^{64}$. Al voto de Francisco de Varas en la Corte ante el Consejo de Estado y en la Junta de 1722 no se le ha dado la importancia que se merece, quizás debido al trascendente papel que Varas y Valdés desarrolló en el puerto gaditano en ausencia de Patiño en relación a la fluidez de la organización de flotas. No obstante, Francisco de Varas se quejaba del problema de las aduanas y del control de los mercaderes extranjeros. Francisco de Varas se había convertido en un activista anti-corrupción que dejaba en segundo lugar la importancia de la construcción naval que sí estaba en el programa defensor de José Patiño $0^{65}$. La cuestión fiscal de la Casa-Intendencia es un tema muy complejo que aún deja pendiente de analizar factores relativos a cómo funcionaba realmente la aduana de Cádiz, establecida como independiente de la de Sevilla desde $1693^{66}$. Hasta el momento, algunos interesantes trabajos de investigación han considerado este tema visto desde la perspectiva estatal, en el marco de la compleja reforma de la armada y sus vicisitudes, generalmente concurridas con problemas de corrupción ${ }^{67}$. En relación a la cuestión del control fiscal, este interés explica en cierta forma por qué este traslado se hizo de forma muy paralela a la reforma de la Hacienda a principios del siglo xviII. Según afirma Dubet, el período entre 1717 a 1724 se caracterizó por la confrontación de varios modelos, así como por enfrentamientos entre partidos, por la corrupción (sobre todo durante la época en la que Nicolás de Hinojosa era tesorero mayor) y por la inflexión de la política crediticia de la corona española ${ }^{68}$. Sabemos que Patiño redactó una instrucción de intendentes hacia 1718 con prerrogativas en justicia, policía y finanzas, por lo que es una hipótesis plantear que los procesos de las reformas de la Hacienda y la tesorería se enmarcan con el debate sobre el traslado de la Contratación y el establecimiento que uniese en Cádiz un mando unificado para la fiscalización del comercio y la marina ${ }^{69}$.

En los proyectos presentados se relacionaban de forma intrínseca la mejora de la Hacienda con la del comercio y la navegación, como el memorial de Pedro Moreno. Este proyecto se dividía en cinco capítulos en uno de los cuales se hacía

64. Ravina Martín, M.: El pleito, pp. 83 y ss.

65. AGI, Arribadas 192. Memorial de Francisco de Varas y Valdés, «Dictamen sobre la restitución del comercio, internación de extranjeros y restablecimiento de la Aduana de Sevilla».

66. Crespo Solana, A.: La Casa de la Contratación, p. 141.

67. Como en la completa obra de Dubet, A.: La Hacienda Real de la Nueva Planta (17131726), entre fraude y buen gobierno. El caso Verdes Montenegro. Madrid, Fondo de Cultura Económica, 2015.

68. Idem, pp. 40 y pp. 81 y ss.

69. Idem, p. 82; Crespo Solana, A.: La Casa de la Contratación, pp. 141 y ss. 
hincapié en la necesidad de estudiar la manera de restablecer el comercio y las fábricas, así como la navegación. Para ello se apostaba por la centralización (incluso en cuestiones lingüísticas), así como por desterrar la idea de la incompatibilidad entre nobleza y negocio. Afirmaba que «todo noble, hidalgo o caballero cruzado solo podía servir al rey pero podían negociar sin degradarse en toda clase de mercancías ${ }^{70}$. Pedro Moreno solicitaba reformar la real Hacienda y modificar las plantillas, reduciendo el personal y las clases de impuestos, estableciendo en cada provincia un banco o pósito. En Madrid, una intendencia general debía de sustituir al Consejo de Hacienda. También se debía castigar el contrabando. Aunque la reforma de la Hacienda es un tema complejo que abarca aspectos institucionales, territoriales, políticas de gastos y asuntos militares, como ha demostrado la valiosa bibliografía al respecto, fue sin duda la cuestión relativa a la recaudación de las rentas, en este caso procedentes del comercio privado, lo que determinó la creación de una Intendencia de marina que buscaba la aplicación de este control a las necesidades derivadas del apresto de flotas, su defensa armada y la gestión de la guerra. Como bien declaró Anne Dubet, existía un paralelismo o analogía entre la creciente centralización y la pervivencia aún de las múltiples formas de administración indirecta a través de asientos y arrendamientos ${ }^{71}$. Lo que sí estuvo claro era la necesidad de establecer un modelo de naturaleza «fiscal militar», razón que incidió en las reformas de algunas de las instituciones ya avanzado el siglo xviII, como el caso de la Tesorería Mayor estudiada por Rafael Torres Sánchez ${ }^{72}$. Aunque esta circunstancia se reforzó décadas después, influyó sin duda en las reformas de la década de 1720 con sus formas de control financiero, liderada primero por los ministros franceses, después por el marqués de Campoflorido (en 1709-1711 y entre 1717 y 1724); por Fernando Verdes Montenegro y secundada por el propio José Patiño, en una compleja trama de conspiración y relevos ${ }^{73}$. La política impuesta por Nicolás de Hinojosa y Patiño dio lugar a la relación de la Tesorería General con dependencias (pagadurías) en «todas las provincias tuteladas por intendentes de provincias» ${ }^{74}$. El marqués de Campoflorido se benefició de las contratas de intendencia de los ejércitos de Felipe de Borbón durante la

70. AHN, Estado 2927, n. ${ }^{\circ} 306$.

71. Dubet, A.: «Comprender las reformas de la Hacienda a principios del siglo XVIII. La buena administración según el marqués de Campoflorido», Revista HMiC: història moderna $i$ contemporània, 10,2012 , pp. 20-51.

72. El autor analiza la institución durante el reinado de Carlos III: ToRres SÁnCHES, R.: La llave de todos los tesoros. La Tesorería General de Carlos III. Madrid, Sílex, 2012.

73. Este último caso estudiado por Dubet, A.: La Hacienda Real.

74. Dubet, A.: «Comprender las reformas...», p. 26. 
ANA CRESPO SOLANA

LA INTENDENCIA DE MARINA Y EL «GOBIERNO DE LA CONTRATACION»:

EL SUEÑO NAVAL DE JOSÉ PATIÑO Y ROSALES (1717-1736)

Guerra de Sucesión Española (desde 1704 para la zona de Galicia) y tuvo también el arriendo de las salinas de Andalucía.

\section{Proyectos de construcción naval y flotas de Indias}

En este contexto histórico se subraya la importancia de Cádiz como centro naval y carenero. Indudablemente, la creación del astillero de la Carraca, espléndidamente estudiado por Quintero González, supone una confirmación definitiva del proyecto industrial-naval gaditano ${ }^{75}$. Este proyecto naval que, aunque no estaba explícitamente incluido en el plan de Andrés de Pes, sí lo estaba en las ideas de Patiño de reconversión de los antiguos careneros de la bahía de Cádiz. El proyecto del astillero pretendía unificar las habilidades portuarias y de construcción naval, carenado y atención a los barcos que arribaban y salían del puerto en un área especialmente diseñada para ello, y que antes se encontraban esparcidas por varios lugares relacionados con el antiguo Real Carenero de Puerto Real y que ahora se ubicaría en un islote al norte de la Isla de León. Esto supuso, entre otras cuestiones, la utilización de caños como zonas de carenado natural y de almacén de maderas para su estudio y aplicación constructiva. Actualmente los caños de la Carraca aún contienen restos de madera histórica almacenada que bien podrían ser objeto de estudios dendrocronológicos y de arqueología experimental. El significado histórico de las anteriores atarazanas y, sobre todo, del Real Carenero, se comprendía por la problemática de la denominada Barra de Sanlúcar, en el estuario del río Guadalquivir, que presentaba problemas de navegación para acceder a Sevilla. De hecho, puede decirse que quizás uno de los factores más determinantes del traslado a Cádiz fue el discurso sobre la seguridad de los barcos de la flota de Indias y su modelo de construcción. El uso de navíos de mucho calado hacía difícil la subida por el Guadalquivir, aunque aún no se ha profundizado mucho en cómo pudo afectar esto a la construcción de los barcos de la flota de Indias. El aumento del tonelaje de los galeones complicaba su remonte por el río hasta Sevilla. Quizás por ello las armadas de escolta que conducían la plata estaban autorizadas a fondear en Cádiz para evitar los problemas del calado fluvial. En 1672 el Consejo y Junta de Guerra exigió que los barcos «sean más planudos, de menos puntal que el correspondiente a su manga y demanden menos agua que los disponibles en atención a los mismos condicionantes» ${ }^{76}$.

75. Quintero GonzÁlez, J.: El arsenal de la Carraca (1717-1736). Madrid, 2000.

76. Comentarios citados en Crespo Solana, A.: «Cádiz y el comercio...», citando a Serrano Mangas, F.: Armadas y flotas de la plata (1620-1648). Madrid, Banco de España, 1989, p. 22; y O’Donnell y Duque De Estrada, H.: «Defensa militar de los reinos de Indias», en Historia

Ediciones Universidad de Salamanca / 요 Stud. his., H. ${ }^{a}$ mod., 39, n. 2 (2017), pp. 75-114 
El discurso de José Patiño sobre la naturaleza de la bahía de Cádiz como carenero natural y lugar excelente para el almacenamiento de maderas para la construcción naval es especialmente relevante en su discurso de voto en la Corte por el traslado de la Contratación ${ }^{77}$. Pero esto fue la culminación de una serie de hitos que tuvieron lugar desde los primeros años de la guerra de Sucesión y el establecimiento de la Junta para el Restablecimiento del Comercio. Fue en esta Junta, en 1706, cuando el ministro Manuel García de Bustamante presentó un memorial que recalcaba la necesidad de utilizar el puerto acondicionado de Cádiz, idea que, como se ha visto anteriormente, Andrés de Pes haría suya ${ }^{78}$. En esa junta, con participación de ministros franceses, Nicolás Mesnager presentó un plan para construir una armada que propició el Real Decreto de Felipe V de 3 de septiembre de 1708 para la construcción de 20 barcos. Estas propuestas siempre chocaban con la falta de financiación ${ }^{79}$. El conde de Bergeyck presentó también, en 1711, dos propuestas para potenciar dos astilleros, en Cantabria y en Andalucía, así como un plan de abastecimiento que afectaba a la recogida de madera en el norte y en el sur de la Península Ibérica. Al parecer, esta influencia no fue solo francesa sino flamenca ${ }^{80}$. En 1713 el ministro José Grimaldo encargaría un plan a Antonio de Gaztañeta para consolidar la construcción naval en las dos zonas norte (representado por Guarnizo) y sur (representado por Cádiz). A esta llamada Gaztañeta respondió con un memorial fechado en $1723^{81}$. Mientras tanto se inició una importante reactivación de los viajes de las flotas de Indias. Un Memorial escrito por Bernardo Tinajero de la Escalera presentado a modo de «informe» en fecha del 15 de enero de 1713 describía una: «Planta o Proyecto, que en virtud de orden de S.M. ha formado el Sr. D. Bernardo Tinajero de la Escalera, del Consejo de S.M. y su secretario en el Real de las Indias y Junta de Guerra de ellas». Se encargó el plan de construcción a Manuel López Pintado, que diseñó la fabricación de 10 navíos. El documento, aparte de lo técnico, hacía hincapié en la necesidad de establecer fábricas de bajeles, «...supuesto este verdadero, principio tan innegable, como patente concurre el que por hoy mira esta construcción de fábricas para solo la precisa, como importante navegación a las Indias, la cual sin navíos de guerra

militar de España. Edad Moderna: Ultramar y la Marina, t. 3, vol. 1. Madrid, Ministerio de Defensa, 2013, pp. 81-99.

77. Crespo Solana, A.: La Casa de la Contratación, pp. 118-127. El documento está en AGI, Arribadas, 10 et passim.

78. AGI, Indiferente General, 2046 A. Documentos de la Junta de Comercio. Memorial de Manuel García de Bustamante.

79. Pérez-Mallaína Bueno, P. E.: «La marina de guerra española...».

80. Crespo Solana, A.: «Las reformas del comercio gaditano...», p. 192.

81. AHN, Estado, 2938 (vid. ut supra nota 20). 
que convoyen las flotas no se puede lograr» ${ }^{82}$. En 1711 Bernardo Tinajero de la Escalera había creado también un proyecto para el despacho de una flota a Nueva España $^{83}$. El documento recoge una serie de ordenanzas que pretendían fijar un protocolo de actuación para la organización de las flotas de Indias y que fue vista en la Junta de Comercio ${ }^{84}$. Como miembro del Consejo de Indias, la Junta de Comercio y fiscal de la Junta, Bernardo Tinajero dictaminó que estas ordenanzas debían regir el tráfico de las Indias entre los vasallos del rey, pero comprendiendo también a aquellos nacionales con cuyas naciones se tuviese paz y amistad. No obstante, se seguía manteniendo que la navegación a las Indias y la entrada en los puertos de América era solo para los españoles, quedando prohibido a los «otros súbditos de España» y quedaba prohibida la entrada a los navíos extranjeros en los puertos de América. Una cláusula estimaba que:

A todos los súbditos de mi corona a quienes por ley está prohibido comerciar en las Indias y a los extranjeros amigos y aliados de esta Corona será permitido que por mano de españoles y en navíos que pertenezcan a estos (aunque sea de fábrica extranjera) y no en otra forma puedan enviarles desde Andalucía a las Indias en su nombre todas las mercaderías que quisiesen en poca o mucho cantidad ${ }^{85}$.

De alguna manera y, a pesar de las contradicciones, la nueva dinastía reconoce la necesaria connivencia de los extranjeros en el comercio de Indias. Pero las ordenanzas para la flota expuestas por Bernardo Tinajero disponían interesantes aspectos de tipo logísticos. La flotilla debía componerse de siete bajeles, «los de guerra, uno para capitana y el otro para refuerzo o gobierno y los cinco restantes para marchantes». La primera carga que debían de recibir los navíos de guerra era 4 mil quintales de azogue, unas bulas de la Santa Cruzada y papel sellado «correspondiente al gasto de un año de aquel Reino». El buque restante de la capitana y el refuerzo podía carga ropas y frutos del comercio:

pagando este a los individuos interesados sus fletes según el prefinido que se dirá en su lugar, de forma que dichas naos puedan jugar su artillería y salir a su viaje marineras

82. Cita en Martínez González, A. J.: «Las ordenanzas», p. 195. AGI, Santo Domingo 482.

83. «Proyecto para el despacho preciso de una flotilla para las provincias de Nueva España en este presente año de 1711. La cual ha de salir a navegar de los puertos de Andalucía, con expresión de los vasos de que se ha de componer...», Zaragoza, 21 de abril de 1711, firmado por Josep Grimaldo y Bernardo Tinajero. Citado en Delgado Ribas, J. M.: Dinámicas imperiales (1650-1796). España, América y Europa en el cambio institucional del sistema colonial español. Barcelona, Bellaterra, 2007.

84. "Ordenanzas nuevas que se han de publicar y observar para el comercio y tráfico de las Indias, entre los vasallos de estos Reinos con los de aquellos dominios...», BNE, mss. 12055 (H.224R-253R).

85. Ordenanzas nuevas que se han de publicar, fol. 225. 
y defensas sin que lo impida la carga, para cuyo puntual cumplimiento serán visitadas por el gobernador y ministros del tribunal, a quienes toca, y dichos fletes, $\mathrm{y}$ aprovechamientos de cuenta de la Real Hacienda, por lo que mira a la Capitana, en la forma y por los términos, que cuando la llevó el General Don Andrés de Pes ${ }^{86}$.

Al regreso, la capitana y el refuerzo debían traer los caudales pertenecientes a la Real Hacienda, salarios del consejo, y Bolsas fiscales; en la capitana debían ser cargados las dos tercias partes y el restante en el refuerzo. En estos barcos se cargaba también la plata, oro, grana y añil. El rey nombraría tres diputados que han de ir y volver en dicha flota. A parte de las normativas para la organización de la flota y la especificación de todos los derechos que debían pagarse por las mercancías permitidas o aceptadas a comercio ${ }^{87}$, las ordenanzas de flotillas y flotas incluían una serie de normativas para los cobros del flete de cada mercadería, que se tenía que pagar a los dueños de los navíos. Respecto a los derechos se refería que se debían de pagar en contado y entrar enteramente su importe en la Tesorería Mayor de la Guerra, cuyos ministros eran nombrados por el rey,

y mandará expedir las instrucciones, que los referidos deben observar, y en ellas los oficios por donde deben despachar, excluyendo desde luego a todo género de Arrendadores de rentas y impuestos por cualquiera calidad, y condición que sean, pues no han de tener ninguna intervención en todo lo referido ${ }^{88}$.

Y se aceptaba también que como el importe de todos los derechos iban a la Tesorería el arrendador de Almojarifazgo de la aduana estaba exento pues de satisfacer el aumento por no recibir el pago de los derechos. Esto afectaba también a otros arrendadores de regalía, vino, vinagre y aceites. Las guías, medidas y cobranza de derechos por los ministros del rey solo debían llevarse a cabo en Sevilla y Cádiz. En el caso de El Puerto de Santa María y Sanlúcar solo se les debía de dar un pase para que los ministros que residiesen en Cádiz,

precediendo la obligación de llevar precisamente a la playa de dicha ciudad a medir, reconocer y pagar los derechos de los géneros que hubieren de embarcar, a los

86. «Proyecto para el despacho preciso de una flotilla», et passim.

87. Hacían cuenta detallada de quintales de hierro, cajones de herraje, marquetas de cera, churlas de canela, cajón de acero, lienzo crudo, géneros de hilos de Flandes, balón de papel, barril quintaleño de pasas y almendras, balas de pimienta, botija de vino, barril de vino, arroba de aceite, pipa de vino, aguardiente, géneros de mercerías, que se pagaban por palmeo. «Proyecto para el despacho preciso de una flotilla para las provincias de Nueva España en este presente año de 1711. La cual ha de salir a navegar de los puertos de Andalucía, con expresión de los vasos de que se ha de componer».

88. Ibidem. 
cuales, cogiéndolos en extravío, les han de recaer las penas que van impuestas en la primera clase ${ }^{89}$.

Los productos de lujo, como la plata, oro, grana añil y «demás frutos», estaban sometidos a otros derechos y contribución en los viajes de retorno. Aquí también se incluía los curtidos de pieles, azúcar, el palo de brasilete y el Campeche, el cacao, tabaco, achote, vainilla, grana. Los derechos debían de pagarse a la entrada en los reinos de España, a la vuelta de las Indias. En los puertos de salida debían de hacer registro estricto de todo lo que se embarcase con la intervención de los oficiales reales de los puertos y de los diputados de la flota, pero sin tener que abrir ningún cajón para el registro, ya que los dueños darían relaciones juradas de su marca, número y calidad y cantidad para que se verificasen y reconociesen una vez llegados a España y se procedería contra quien hubiese faltado a la verdad. Se debía tomar nota puntual de todo lo que se embarcarse y qué navío iba remitiendo copia original de todo al Consejo de Indias. La no observancia de dicho registro incurría en penas para comerciantes, dueños de navíos y maestres. Los ministros que toleraran el incumplimiento de las normas también se verían sometidos a la pena de privación de empleo. El deseo de la «vía reservada» y la centralización en el control del apresto de flotas es algo que irá creciendo en las primeras décadas del siglo xviII, tal como se aprecia en las ordenanzas de flotas y flotillas ya durante la Guerra de Sucesión. La guerra aminoró el devenir de estos aprestos y salidas de flotas, aunque las ordenanzas para la organización de ellas son muy explicativas de los inicios de este proceso de centralización. La ordenanza para la flota de 1711 fue apoyada por Josep Grimaldo en Zaragoza, a 21 de abril de 1711 y firmada por Bernardo Tinajero ${ }^{90}$.

Estos proyectos de reactivación de las flotas y acopio de recursos para la construcción naval afectaban también a la cuestión colonial. Se propuso entonces el desarrollo de unos astilleros en Cuba y la consideración de Panzacola, como una zona donde «existían árboles de calidad superior que lograban hacer que los barcos sobrepasasen los 30 años de vida activa ya que eran abundantes las Indias de ricas y preciosas maderas para el expresado fin, es igual el bien, por lo que mira a palos para arbolar de todas las calidades y tamaños». Y opinaba que los navíos construidos en Europa tenían una duración mucho menor y había que estar continuamente reparándolos ${ }^{91}$.

89. Ibidem.

90. Proyecto para el despacho preciso de una flotilla, et passim.

91. Este documento también está en BNE, mss. 12055. 
Tras su nombramiento como intendente-presidente, Patiño elaboró él mismo un Proyecto para el despacho de la flota para las provincias de Nueva España el 10 de marzo de $1717^{92}$. Es necesario incluso volver al testimonio del voto de José Patiño en la Corte algunos años después y que hemos sucintamente comentado antes. Patiño describe importantes cuestiones de tipo técnicas referentes a la navegación y a la construcción naval, pero soslaya o, al menos, no quiere que se trasluzca que ya se ha comprometido con el sector privado en relación a la financiación comercial, los aprovisionamientos de arsenales y el carenero, así como otros negocios subyacentes entre los que estaba, sin duda, el transporte y avituallamiento de madera ${ }^{93}$. Por su parte, el Memorial de Antonio Gaztañeta de 1723, manuscrito en forma de informe enviado al marqués de Grimaldo, es posterior a sus ya conocidos trabajos sobre construcción naval que le convirtieron en el adalid de la construcción naval según el modelo español en Guarnizo ${ }^{94}$.

\section{Vicisitudes con las flotas de Indias durante la intendencia de Fran- CISCO DE VARAS Y VALDÉS}

Cuando Francisco de Varas y Valdés fue nombrado intendente de marina en 1715 , ahora con atribuciones propias del oficio y no dependiente de la Superintendencia como en 1711, siendo primero en tener el empleo en Andalucía, se le mandó visitar los careneros y arsenales para establecer la marina. Comunicó el «infeliz estado en que los había hallado, porque siendo único arsenal que había dado el del Real del Puente Suazo, estaba tan abandonado, que lo encontró sembrado de hortalizas» ${ }^{95}$, ordenó que se establecieran los almacenes precisos para los pertrechos y municiones de bajeles y oficinas de carenas. En ese año colaboró con Manuel López Pintado en los trabajos de carenado y pertrechado de la flota de Nueva España. La llegada de Patiño en 1717 supuso el aumento de las disposiciones para este sentido. El intendente-presidente, además de encargarse de la logística y financiación de las flotas, debía propiciar la construcción de buques de guerra (hoy llamados «buques de Estado»). Al parecer, Patiño hizo aumentar las actividades de los careneros de la Carraca y perfeccionó las dependencias de los astilleros hacia $1724^{96}$.

92. AGI, Impresos Antiguos, 16/5. Impreso. Cádiz, 10 de marzo de 1717.

93. AGI, Arribadas, 10, et passim.

94. Baudot Monroy, La defensa..., p. 79, et passim.

95. Francisco de Varas y Valdés, puesto a los pies de V. M., dize: Que en todo el tiempo que ha tenido la honra de servir a V. M., fol. $24 \mathrm{v}$.

96. AHN, Estado, leg. 3208, n. ${ }^{\circ} 345$, fols. 313-314. 
Pero en la práctica portuaria, los años comprendidos entre 1717 y 1730 conocieron muchos altibajos en lo referente a la preparación en el puerto de las flotas de Indias y la reunión de los buques mercantes y de guerra. Debía haber una manera posible de coordinar ambas cosas: la construcción naval y el apresto de flotas, lo que no siempre era fácil ante la alta demanda del comercio privado, que necesitaba barcos constantemente. Era necesario formar un reglamento de flotas y galeones para el comercio de Indias, debiendo de fabricarse por cuenta del rey navíos de 50 a 80 cañones para participar en esta carrera, tanto como buques de guerra como mercantes. Los capitanes y mercaderes pondrían los oficiales y la guarnición que necesitasen. Se tendría una escuadra en Nueva España y otra en Tierra Firme para que limpiasen aquellas costas de piratas. Una armada protegería por mar a los barcos mercantes, debiendo fortificarse la bahía de Cádiz, El Ferrol y Cartagena, es decir, lo que luego serían los tres departamentos marítimos ${ }^{97}$. Estos hechos son sin duda importantes antecedentes del Real Proyecto de Flotas y Galeones, muy bien estudiado por García-Baquero González y otros especialistas $^{98}$. Aunque inmerso en el marco tradicional administrativo precedente, contiene ahora algunas orientaciones nuevas. Admitía, por ejemplo, los buques de registros y aquellos barcos pertenecientes a las compañías privilegiadas. Los registros iban destinados a aquellas regiones antes marginadas por el sistema de flotas y galeones.

Durante estos años de la Guerra de Sucesión las flotas conocieron muchos avatares. El almirante Manuel López Pintado ya había participado como consignatario de diversas mercaderías que iban a bordo de la flota de Manuel de Velasco, cuando esta sucumbió en Vigo en 1702. López Pintado había sido maestre de plata de la flota del general Diego Fernández de Santillán y desde Veracruz tuvo que pleitear con el propio general y el maestre de permisión por cargar a bordo algunas mercancías que no le fueron consignadas ${ }^{99}$. Como maestre de plata debía hacerse cargo de los productos valiosos, incluyendo el oro, plata, grana y añil, y cobraba el $1 \%$ del valor de la plata transportada. Joseph de Veitia describe que este maestre de plata era un cargo con responsabilidades y gastos, pues tenía que contratar un escribano y dos hombres de su confianza y dejar una fianza en la Casa de la Contratación para cubrir el material a transportar ${ }^{100}$. López Pintado

97. AHN, Estado, leg. 2927, n. ${ }^{\circ} 306$.

98. García-Baquero GonzÁlez, A.: Cádiz y el Atlántico (1717-1778). El comercio colonial español bajo el monopolio gaditano, Cádiz, Diputación Provincial, 2 vols., 2. ${ }^{a}$ ed. 1976, pp. 197-210.

99. AGI, Escribanía, leg. 293A.

100. Citado en Tapias Herrero, E.: «El teniente General López Pintado, cargador a Indias, Jefe de Escuadra y marqués de Torreblanca del Aljarafe», Temas Generales, 2010, pp. 408-417. 
era capitán de mar y guerra en 1710 cuando formalizó un asiento con la corona para transportar 7.000 quintales de azogue, pero además, participó en un rocambolesco experimento para demostrar la navegabilidad de la barra de Sanlúcar en el que se enfrentó a Antonio Gaztañeta, que debía demostrar la realidad de la no navegabilidad de la zona ${ }^{101}$. Estando en Veracruz, López Pintado tuvo que abrir una investigación sobre el naufragio de la Armada de Barlovento de Diego Alarcón y Ocaña, quien había resultado culpable del desastre ${ }^{102}$.

Felipe V trató de comprar navíos a Francia, pero al no dar resultados la pauta a seguir por la corona fue de continuar entablando asientos con particulares para la formación de flotas. En 1711 Francisco de Varas desempeñaba el cargo de juez togado del Tribunal de la Contratación de Sevilla y se le encargó el despacho de la flota de Nueva España del general Andrés de Arriola, compartiendo esta misión con el ministro desplazado a Cádiz, marqués de Villagracia, asistente y superintendente de rentas reales en Sevilla. En 1712 asistió al asiento de Antonio de Echevers y Subiza para navegar una escuadra de cuatro navíos a Tierra Firme, por primera vez después de siete años que no se organizaban galeones o navíos sueltos. Varas se tuvo que desplazar a Cádiz para ello, ya que los comerciantes no querían arriesgarse en Tierra Firme debido a lo peligroso que era por el «gran tráfico y comercio que entonces tenían las naciones extranjeras en aquel país y en la notoriedad del ningún valor de las ropas» ${ }^{103}$. En 1712, con el apoyo del ministro Bergeyck y de Bernardo Tinajero, López Pintado propuso al rey la construcción en La Habana de 10 navíos de 800 toneladas y 60 cañones. Pero esta misión quedó interrumpida debido a que la flota que debía de enviar los materiales a Cuba fue enviada por la corona al bloqueo de Barcelona. López Pintado no pudo salir de Barcelona hasta el 12 de noviembre de 1713 con una escuadra de diez buques ${ }^{104}$. A pesar de la dificultad, ya que entonces no había ministros en Cádiz para asistir en las carenas, pertrechado y lastre de los barcos, Varas logró organizar esta escuadra que salió en noviembre para el río Llobregat. De paso también se encargó de aprestar dos avisos para Nueva España, dos embarcaciones para salir al encuentro de la flota de Arriola, otras para servir de escolta; la causa contra Andrés de Gainça sobre introducciones en la costa de Caracas, la extracción de tabacos contra Andrés Enriquez y otros oficiales de mar ${ }^{105}$.

101. Ravina Martín, M.: p. 90.

102. AGI, Escribanía, leg. 115B.

103. Francisco de Varas y Valdés, puesto a los pies de V. Magestad (cit.).

104. Pérez-Mallaína Bueno, P. E.: Política naval española en el Atlántico, 1700-1715. Sevilla, 1982, pp. 405-407.

105. En definitiva todas las atribuciones que luego serían sistematizadas para el intendente de marina en la persona de José Patiño y Rosales. Francisco de Varas y Valdés, puesto a los pies de V. Magestad (cit.) et passim. 
Hacia 1713 y más tarde, en 1715, se ordenó la creación de una Junta en Cádiz compuesta por el gobernador general de la armada, el almirante general Andrés de Pes, entonces gobernador de la plaza, y Francisco de Varas. La Junta se debía reunir cada dos semanas y, al parecer, su objetivo era que Varas y Valdés respondiera de sus actos en Cádiz como organizador de las armadas. En 1714 se le había conferido además a este la Superintendencia general de Azoguez de Andalucía, cargo que desempeñó hasta 1718, cuando se instaló en Cádiz la Intendencia, nombrando subdelegados de provincias ${ }^{106}$. En 1714 Varas y Valdés organizó el despacho de tres navíos del asiento del Marqués de Montesacro para Honduras y Caracas, así como varios encargos por la vía reservada y el Consejo de Indias, asuntos en los que él mismo confiesa haber tenido muchas dificultades. En 1715 estuvo encargado del recibo de los navíos de Buenos Aires y del asiento de Andrés Martínez de Murguía; aprestó y despachó en dos ocasiones la escuadra del asiento de Juan Nicolás Martinet, en un viaje para convoyar la flota, de Ubilla y otro para convoyar la flota de Manuel López Pintado. También despachó la escuadra para conducir a Tierra Firme al virrey de Perú, Príncipe de Santo Bono, y una vez más le costó convencer a los comerciantes a cargar la flota, pues los galeones de Tierra Firme tenían una crisis derivada de la injerencia del comercio extranjero en América, en parte, algo infundado, según el propio Varas y Valdés, que hizo todo lo posible por restaurar esta ruta. En 1715 López Pintado comandó una flota a Nueva España que logró regresar a Cádiz al año siguiente. Francisco de Varas continuó sus labores portuarias en 1716 con el apresto de tres navíos de guerra y dos mercantes para La Habana y Veracruz, unos para conducir al virrey Marqués de Valero y el otro para recoger el «tesoro buceado en el Palmar de Ays» ${ }^{107}$. Llegó a Cádiz el 24 de agosto de ese año, en la flota de Manuel López Pintado y los navíos del comando de Fernando Chacón. La llegada de este tesoro buceado satisfizo al comercio tanto que costearon el armamento de los navíos. Una vez más Francisco de Varas hace su mejor trabajo para rehabilitar esta navegación justo en los años posteriores al final de la guerra de Sucesión. En parte, estos años fueron difíciles, es como si el comercio de Indias hubiera perdido credibilidad o se hubiese visto debilitado por la desconfianza de los negociantes y por la falta de medios para aprestar barcos:

la Real Hacienda no se hallaba con medios para costear dicho armamento, ni el comercio para suplirlo, se le encargó al suplicante (Varas y Valdés) se empeñase con las personas de quien tuviera mayor confianza, para que le facilitasen los medios

106. Francisco de Varas y Valdés, puesto a los pies de V. Magestad, fols. 24 y ss.

107. Ibidem. 
necesarios, a fin de que por falta de ellos no cesase un apresto tan conveniente y conociendo su importancia en la mayor brevedad de la salida, buscó entre sus amigos todo el caudal que se necesitó por entonces, sin premio, ni costo alguno de la Real Hacienda, con el cual carenó, aprestó y bastimentó los tres navíos de guerra» ${ }^{108}$.

El hábil intendente en funciones hizo lo mismo en ese año de 1716 con una escuadra de seis navíos de guerra para socorrer al Papa en la campaña de Corfú contra los Turcos; cuatro navíos de guerra para la Mar del Sur. En 1717, a la vuelta de estos navíos, incluidos los de la campaña de Corfú, Varas y Valdés ordenó desarmarlos en La Carraca, y los preparó para conducir víveres y armas a la campaña de Melilla.

El 12 de febrero de 1717 llegó José Patiño a Cádiz con el empleo de «marina e Indias», que con tanto celo había desarrollado Francisco de Varas y Valdés. Su devenir desde ese momento es algo accidentado, pues el rey le llamó a la Corte, en Segovia, para nombrarle secretario del Consejo de Indias, de la parte del Perú, pero inmediatamente le ordenó volver a Cádiz, donde debía ponerse a las órdenes de Patiño, quien le autorizó para que aprestara la flota de Antonio Serrano junto a dos navíos para Tierra Firme que debían navegar en conserva de la flota hasta separarse ${ }^{109}$. Se le encargó también que aprestara seis navíos para el Mediterráneo, 24 embarcaciones para conducir víveres desde Málaga y recibir el navío San Juan junto a otros siete que venían desde Vizcaya cargados de pertrechos y municiones; remitir a Ceuta embarcaciones menores para el servicio militar; dos navíos a Tortosa para cargar palos y maderas para las carenas de la Armada. También recibió tres navíos de La Habana con cargamento del rey, despachó fragatas de guerra para transportar batallones de infantería a los presidios de África. En agosto de 1718 arribó la flota de Nueva España de Antonio Serrano con 12 navíos, uno de ellos viniendo desde Cartagena. Al ser una flota importante, el rey mandó al intendente de marina que fuera duro con la aplicación de las leyes y castigase todo lo que viniese fuera de registro. Se declaró «por comisado más de 240 mil pesos pertenecientes a muchos individuos del comercio, de cuyas crecidas porciones no recibió el suplicante las tercias partes que por derecho le tocaban, por haberlas puesto a los pies de V.M. y remitidlas en las conductas que se mandaron» ${ }^{110}$. En 1719, Francisco de Varas se encargó de recibir la nao nombrada «Nuestra Señora de la Candelaria», desde La Habana, con carga de tabacos de la Real Hacienda, un navío de aviso con pliegos para Buenos Aires, otros avisos para Tierra Firme,

108. Francisco de Varas y Valdés, puesto a los pies de V. Magestad, dize: Que en todo el tiempo que ha tenido la honra de servir a V. Magestad, p. 26 et passim.

109. Ibidem.

110. Idem, p. $28 \mathrm{v}$. 
navíos para La Habana y Veracruz para conducir «crecidas porciones de lona, jarcias, y pertrechos para el establecimiento de la Armada de Barlovento» y azogues, bulas, papel sellado y mercancías de cuenta de la Real Hacienda. Hay que señalar el papel de la corona como mercader, pues consideraba el comercio de Indias como un negocio de Estado y la corrupción casi empezaba por ellos mismos. A veces el rey ordenaba que no se admitiesen efectos del comercio, sino solo de cuenta de la Real Hacienda. En ese año la Corona nombró a Manuel de León para que comprase 175 mil pesos en frutos y mercaderías, encargándoseles que fuesen de las más apreciadas para Nueva España, y él mismo se embarcó en la flota, logrando una ganancia de 600 mil pesos en los retornos. En Cádiz, sin embargo, el propio León tuvo que justificar la pérdida de ese dinero, acusado de haberse quedado con parte del caudal. Francisco de Varas le protegió y defendión ${ }^{111}$. En julio Varas despachó dos embarcaciones al Cabo San Vicente, dando instrucciones para reconocimiento de naos enemigas, y preparó una defensiva ante la llegada de dos barcos, el «Javier» de Tierra Firme y «Nuestra Señora del Carmen», de Nueva España, «cuyos comandantes ignorando el rompimiento con Inglaterra amanecieron dicho día entre una escuadra de 6 navíos de guerra de dicha nación». Fue informado Varas de la situación por las Vigías de Cádiz, por lo que despachó unos barcos bien armados para defender a los navíos españoles y así logró el «Javier» tomar la canal de Sanlúcar, y el otro pudo llegar a la bahía también. Este barco llegaba de retorno con más de un millón y 200 mil pesos. Se tuvo recelo de que la armada inglesa pudiese venir a Cádiz, por lo que Francisco de Varas alertó para que se tomaran medidas para la seguridad de la plaza en cuestiones de artillería. En ese mismo año Francisco de Varas afirma que empezó a trabajar en recoger la información para elaborar el nuevo proyecto de Galeones, flotas y navíos sueltos. Debía recoger toda la información necesaria para poder realizar una correcta exacción de derechos reales. Organizó el cobro en Tierra Firme de los Reales Derechos de la Alcabala antigua y moderna, los almojarifazgos de entrada, a proporción de los cargues, y que hiciese unos aranceles con los derechos que debían percibir todas las oficinas de España y América por la negociación de las Indias.

Ante la marcha de José Patiño, en 1720 Francisco de Varas y Valdés organizó una escuadra de tres navíos de guerra para una expedición secreta y envío de víveres y personal de infantería a bordo de los buques «El Catalán», «El Cambi» $\mathrm{y}$ «La Fidela» con destino a Canarias y a América. En 1721 fue encargado de coger un navío de 800 toneladas para hacer una prueba de calado del río Guadalquivir,

\section{Ibidem.}


en el contexto de los problemas por el traslado de la Casa de la Contratación. En 1721 y 1722 Andrés de Alcaráz y Zuñiga, conde de la Marquina, presentó un memorial sobre la flota de Indias en el que exponía que el excesivo buque y valor de las flotas y galeones, hacían casi nulas las utilidades del comercio con Indias. Proponía la formación de una sociedad o compañía con ayuda del erario que fuera capaz de abastecer toda América y acabar con el comercio ilícito de los extranjeros, aumentar la marina y los derechos de aduanas, eliminándose así el desorden del comercio por registros sueltos que tanto beneficiaba a la participación extranjera. Se trata de una representación sin fecha con un oficio de Andrés de Pes al marqués de Tolosa manifestando que no tenía nada que añadir al informe que anteriormente había redactado sobre el proyecto de Marquina. Y ello a pesar de que sabemos bien que Andrés de Pes estaba a favor de la creación de esa supuesta «compañía Armada de Indias» ${ }^{112}$. El ministro intentó conocer el parecer de Fr. Guillermo D'Aubenton, pero este manifestó que el asunto le era ajeno ${ }^{113}$. Por su parte, el conde de la Marquina expuso que los puntos que había reservado de su proyecto sobre el comercio de galeones, para decirlos oralmente, correspondían al departamento de extranjeros, por lo que estaba dispuesto a desarrollarlos ante la junta de comercios extranjeros ${ }^{114}$.

En esos años se gestó el Real Proyecto de Flotas y Galeones, cuyos avatares y puesta en marcha es descrita muy bien por Antunes y Acevedo, orientada básicamente a reforzar los procedimientos tradicionales con los que se recaudaban los impuestos, incluyendo una novedad, el derecho de palmeo ${ }^{115}$. Las ordenanzas de flotas parecen repetir esquemas a partir de las reglas impuestas para la flota del general Andrés de Pes. En este cuerpo normativo el Tribunal de la Contratación estaba encargado de notificar jurídicamente y puntualmente a todos los cabos, maestres, capitanes y dueños de navíos de guerra y mercantes, para que no permitan la más leve carga de frutos o ropas sin que se consten en las «guías»:

que han de recoger originales al tiempo del recibo en los navíos haber satisfechos a S.M enteramente todos los derechos que van señalados en la segunda parte de este proyecto, con apercibimiento de que si lo contrario hicieren o consistieren se ha de pasar desde luego a prisión de sus personas, y perdición de sus navíos, resultando

112. AHN, Estado, leg. 3188, n. ${ }^{\circ} 360$, Madrid, 1 de enero de 1720

113. AHN, Estado, leg. 3188, n. ${ }^{\circ}$ 360, Madrid, 3 de marzo de 1721.

114. AHN, Estado, leg. 3188, n. ${ }^{\circ} 360$, Comunicación de Marquina ofreciendo el memorial al marqués de Grimaldo, Cádiz, 13 de abril de 1722. Impreso, s.f.

115. García-Baquero González, A.: Cádiz, p. 198 y ss. Antúnez Acevedo, R.: Memorias bistóricas sobre legislación y gobierno del comercio de los españoles con las colonias en las indias occidentales. Madrid, 1797. 
para en cuando a sus personas la pena de presidio por tres años, y la privación de no poder navegar a las Indias en estos diez, y que esta diligencia haya de hacer el tribunal se ponga por cabeza del Registro que se formase por cada navío, remitiendo copia de ella al Consejo de las Indias, para que en ningún tiempo puedan alegar ignorancia, ni de otro motivo en que se pueda impedir la referida pena ${ }^{116}$.

Los navíos de una flota debían ir y regresar en conserva bajo el mando del general. Contravenirlo era severamente castigado. Cualquier mercader que quisiese embarcar en la flota llevando cargamento podía hacerlo sacando la licencia necesaria del Tribunal de la Contratación. Sin ella solo iba la tripulación y los ministros que fueren con empleos en las naos, y estos no debían embarcar cargamentos a su nombre. Si defraudaran se les confiscarían los géneros para la Real Hacienda, ellos irían a prisión por tres años y se verían privados de navegar a las Indias. Si pedían licencias para comerciar la Casa de la Contratación debía remitir copia al Consejo de Indias, "para que en todo tiempo conste, previniéndose que no les ha de sufragar para no quedar incusos en las penas el que hagan manifiesto en Puerto Rico, ni en la Veracruz de las mercaderías, y efectos de que no hubiesen pagado derechos, ni el exemplar que sobre esto se observó en la última flota de D. Andrés de Pes, porque no ha de ser de ningún valor» ${ }^{117}$. En 1722 la situación de la navegación desde el puerto de Cádiz parecía tan segura que Jean Pierre Ricard, en su Négoce d'Amsterdam (1722), afirmaba que desde Cádiz solían partir para América de 12 a 20 navíos destino sobre todo a La Habana, Veracruz y Portobello y que los comerciantes vendían allí su mercancía al precio que fuere con tal de no devolverla a España ${ }^{118}$.

\section{A MOdO DE CONCLUSIÓN}

En el contexto bélico de la Guerra de Sucesión a la corona de España y las décadas posteriores, la Monarquía Hispánica tenía razones para reforzar la armada y el comercio colonial de forma unificada. Iba en ello el prestigio y también el futuro de la nueva monarquía Borbónica instaurada en el trono de España. Durante algunas décadas se aprecia claramente la influencia francesa en unas reformas y reorganizaciones que en realidad pretendían reforzar el negocio de estado, unido a un plan auténtico y práctico de construcción de una armada centralizada y estatal. Esto se consiguió a pesar de las reiteradas y desaforadas campañas bélicas en el Mediterráneo y en el Atlántico que solo hicieron atrasar aquel plan de desarrollo naval. En ese contexto bélico las economías nacionales y

116. «Proyecto para el despacho preciso de una flotilla».

117. Ibidem, Delgado Ribas, J. M.: Dinámicas imperiales...

118. Ricard, J. P.: Négoce d'Amsterdam. Ámsterdam, Imprenta Etienne Lucas, 1722. 
la defensa de los mercados se fundamentaban en un mercantilismo que priorizaba el comercio exterior y la construcción de una economía de guerra naval basada en la existencia de una marina fuerte para la defensa de las rutas marítimas y las áreas productivas de influencia, dícese mercados coloniales. Esto influyó mucho en Andalucía, donde el comercio colonial era un sector altamente especulativo por excelencia en el que por vías legales o ilegales se obtenían beneficios que afectaban a diversos sectores de la población tanto autóctona como extranjera. Aunque salió del ámbito protector de una antigua escuela de estadistas y marinos, que defendían, como Andrés de Pez, la creación de una compañía armada para el comercio de Indias, José Patiño logró, tras muchos obstáculos, poner en marcha su proyecto de desarrollo naval y comercial en la bahía de Cádiz. Con la guerra de sucesión de por medio, la influencia de los ministros franceses y las oposiciones de las élites monopolizadores del comercio de Indias, Patiño convirtió viejos proyectos de compañías y desarrollo comercial en un plan unificado que se localizaría en la bahía de Cádiz como centro geográfico por excelencia, junto a otras áreas como la costa vasco-cántabra y gallega, que también estaban presenten en estos discursos político-económicos y en los planes de los marinos-constructores de barcos como el propio Antonio de Gaztañeta. Junto a las circunstancias referentes al comercio (sobre todo fiscales y de control de productos cargados en las flotas) estaba el problema de los barcos, pues sin ellos no se podía llevar a cabo el comercio de Indias. Entre los años de 1717 a 1746 se abrió un período de recuperación de las flotas que cruzaron el Atlántico, que se materializó en un resurgimiento del comercio colonial protagonizado también por los navíos de registros y de la participación de mercaderes extranjeros en flotas y registros. Sin duda, el período de la Guerra de Sucesión y el cambio dinástico en España, con sus consecuentes nuevos gobiernos reformistas, propició que la bahía de Cádiz fuera el centro de los cambios que la Corona deseaba llevar a cabo en la logística y organización del sistema de flotas y galeones. Interesante fue el mano a mano de José Patiño con Francisco de Varas y Valdés, opositor este al traslado de los tribunales y receloso siempre de la poderosa influencia extranjera.

\section{BIBLIOGRAFÍA}

Abbad, F. y Ozanam, D.: Les Intendants espagnols du xvilie siécle. Madrid, 1992.

Acosta Rodríguez, A., González Rodríguez, A. y Vila Vilar, E. (coords.): La Casa de la Contratación y la navegación entre España y las Indias. Sevilla, Universidad de Sevilla, CSIC, Fundación El Monte, 2003.

ANDERSON, A.: An historical and chronological deduction of the origin of commerce: from the earliest accounts. Containing a history of the great commercial interests of the British Empire. To which is prefixed an introduction, exhibiting a view of the 
ANA CRESPO SOLANA

LA INTENDENCIA DE MARINA Y EL «GOBIERNO DE LA CONTRATACION»: EL SUEÑO NAVAL DE JOSÉ PATIÑO Y ROSALES (1717-1736)

ancient and modern state of Europe; of the importance of our colonies; and of the commerce, shipping, manufactures, fisheries, Ec., of Great-Britain and Ireland; and their influence on the landed interest. With an appendix, containing the modern politico-commercial geography of the several countries of Europe. Carefully rev., cor. and continued to the present time..., Impr. John Walker, 1787.

Antúnez AcEvedo, R.: Memorias históricas sobre legislación y gobierno del comercio de los españoles con las colonias en las indias occidentales. Madrid, 1797.

ARAQUe Jiménez, E.: Los últimos pineros. El transporte fluvial de madera desde las sierras de Segura y Cazorla (1894-1950). Jaén, Universidad de Jaén, 2016.

Barea Ferrer, J. L.: «La importancia de Cádiz a fines del siglo xvir: el arriendo de las aduanas», en La burguesía mercantil gaditana, 1650-1868. Cádiz, Instituto de Estudios Gaditanos, Diputación Provincial, 1976, pp. 131-137.

Baudot Monroy, M.: La defensa del Imperio. Julián de Arriaga en la Armada (1700-1754). Murcia, Ministerio de Defensa, Universidad de Murcia, 2012.

Bustos Rodríguez, M.: «La ciudad de Cádiz y su contribución militar a la Guerra de Sucesión española, 1704-1705», Anales de la Universidad de Cádiz, 1, 1984, pp. 139-148.

Bustos Rodríguez, M.: «Cadix, temps et destin d'une ville atlantique à l'époque moderne (XVIe-XVIIe siècles)». La Ville maritime. Temps, especes et représentations. Brest: Université de Bretagne Occidentale, 1996, pp. 149-160.

Bustos Rodríguez, M.: Cádiz en el sistema atlántico. La ciudad, sus comerciantes y la actividad mercantil (1650-1830). Madrid, Sílex, 2005.

Caballero Juárez, J. A.: El régimen jurídico de las armadas de la Carrera de Indias, siglos XVI y XVII. México, 2001 (consulta online: http://www.bibliojuridica.org/libros/ libro.htm?l=163).

Calderón Ortega, J. M.: El Almirantazgo de Castilla: Historia de una institución conflictiva (1250-1560). Madrid, 2003.

Castro, A. de: Vida del Almirante Don Andrés de Pes, ministro de Marina. Cádiz, Imprenta de la Revista Médica, 1879.

Ceballos-Escalera y Gila, A.: El Almirantazgo General de España e Indias en la Edad Moderna. Madrid, Real Academia de la Mar, 2012.

Crespo Solana, A.: La Casa de la Contratación y la Intendencia General de Marina en Cádiz (1717-1730). Cádiz, Universidad de Cádiz, 1996.

Crespo Solana, A.: «A Change of Ideology in Imperial Spain? Spanish Comercial Policy with America and the Change of Dynasty (1648-1740)», en ONNEKINK, D. y RommeLSE, G. (eds.): Ideology and Foreign Policy in Early Modern Europe (1650-1750). Londres, Ashgate, 2011, pp. 215-243.

Crespo Solana, A.: «Confianza, cooperación y competencia en los mercaderes europeos. Mecanismos sociales en los documentos sobre pleitos entre mercaderes en Cádiz en el siglo XViII», en Vila Vilar, E. y Lacueva Muñoz, J. J. (coords.): Mirando las dos orillas: intercambios mercantiles sociales y culturales entre Andalucía y América. Sevilla, Fundación Buenas Letras, 2012, pp. 209-227. 
ANA CRESPO SOLANA

LA INTENDENCIA DE MARINA Y EL «GOBIERNO DE LA CONTRATACION»: EL SUEÑO NAVAL DE JOSÉ PATIÑO Y ROSALES (1717-1736)

Crespo Solana, A.: «The Wider World: Spatial Expansion and Integration in the Hispanic Atlantic, 16th to 18th Centuries», en Crespo Solana, A. (ed.): Spatio-Temporal Narratives. Historical GIS and the Study of Global Trading Networks (1500-1800). Londres, Cambridge Scholar Publishing, 2014, pp. 1-45.

Crespo SolanA, A.: "Cádiz y el comercio de las Indias: un paradigma del transnacionalismo económico y social (siglos XVI-XVIII)", e-Spania. Revue interdisciplinaire d'études hispaniques médiévales et modernes, 25, 2016 en: http://e-spania.revues.org.26016; DOI: 10.4000/e-spania.26016.

Delgado Ribas, J. M.: Dinámicas imperiales (1650-1796). España, América y Europa en el cambio institucional del sistema colonial español. Barcelona, Bellaterra, 2007.

Díaz Ordóñez, M.: Amarrados al negocio. Reformismo borbónico y suministro de jarcia para la Armada Real (1675-1751). Madrid, Ministerio de Defensa, 2009.

Dubet, A.: «Comprender las reformas de la Hacienda a principios del siglo XviII. La buena administración según el marqués de Campoflorido", Revista HMiC: història moderna i contemporània, 10, 2012, pp. 20-51.

Dubet, A.: La Hacienda Real de la Nueva Planta (1713-1726), entre fraude y buen gobierno. El caso Verdes Montenegro. Madrid, Fondo de Cultura Económica de España, 2015.

García-Baquero González, A.: Cádiz y el Atlántico (1717-1778). El comercio colonial español bajo el monopolio gaditano. Cádiz, Diputación Provincial, 2.a ed. 1976, 2 vols. pp. 197-210.

García-Baquero GonzÁlez, A.: "Comercio colonial y reformismo Borbónico: de la reactivación a la quiebra del sistema comercial imperial», Chronica Nova, 22, 1995, pp. 105-140.

García-Torralba Péréz, E.: Navíos de la Real Armada 1700-1860. Madrid, 2016.

GIRARD, A.: La rivalidad comercial y maritima entre Sevilla y Cádiz hasta finales del siglo XVIII. Sevilla, Renacimiento, 2006, pp. 92-114.

KAMEN, H.: «El establecimiento de los intendentes en la administración española», Hispania. Revista Española de Historia, 24, 1964, pp. 63-76.

López Arandia, M. A.: «Maderas del rey. Aprovechamientos madereros en la provincia marítima de Segura de la Sierra», en Araque Jiménez, E. y Moya García, E. (coords.): Aprovechamientos madereros en los montes jiennenses (siglos XIII-XX). Jaén, 2012, pp. 13-78.

Martínez GonzÁlez, A. J.: «La elaboración de la Ordenanza de Montes de Marina, de 31 de enero de 1748, base de la política oceánica de la monarquía española durante el siglo XVIII", Anuario de Estudios Americanos, 71:2, 2014, pp. 571-602.

Martínez González, A. J.: Las superintendencias de Montes y plantios (1574-1748). Derecho y politica forestal para las armadas en la Edad Moderna. Valencia, Tirant lo Blanch, 2015.

Martínez Navas, I.: «El Tribunal del Santo Oficio de Logroño y Don José del Campillo y Cossío», Berceo, 140, 2001, pp. 275-292. 
ANA CRESPO SOLANA

LA INTENDENCIA DE MARINA Y EL «GOBIERNO DE LA CONTRATACION»: EL SUEÑO NAVAL DE JOSÉ PATIÑO Y ROSALES (1717-1736)

Martínez Shaw, C.: «El tercio de frutos de la flota de Indias en el siglo xvin», Archivo bispalense: Revista histórica, literaria y artística, tomo 56, n. ${ }^{\circ} 171-173,1,1973$, pp. 201-211.

Muro Orejón, A.: Cedulario Americano del siglo XVIII, tomo II. Sevilla, 1969.

O’Donnell y Duque de Estrada, H.: «Defensa militar de los reinos de Indias», en Historia militar de España. Edad Moderna: Ultramar y la Marina, t. 3, vol. 1. Madrid, Ministerio de Defensa, 2013, pp. 81-99.

Ormrod, D.: The rise of Commercial empires. England and the Netherlands in the Age of Mercantilism, 1650-1770. Cambridge University Press, 2003.

Parker, G.: «¿Por qué triunfó el asalto a Cádiz en 1596?», en Bustos Rodríguez, M. (dir.): El Asalto anglo-bolandés a Cádiz en 1596 y su contexto internacional. Cádiz, Universidad de Cádiz, Ayuntamiento de Cádiz, 1997, pp. 93-124.

Pérez Fernández-Turégano, C.: Patiño y las reformas de la administración en el reinado de Felipe V. Madrid, Ministerio de Defensa, 2006.

Pérez-Mallaína Bueno, P. E.: Política naval española en el Atlántico, 1700-1715. Sevilla, 1982, pp. 405-407.

Pietschmann, H.: «Imperio y comercio en la formación del Atlántico español» en: Oliva Melgar, José M. y Lobato, I. (eds.): El sistema comercial español en la economía mundial (siglos XVII-XVIII). Homenaje a Jesús Aguado de los Reyes. Huelva, Universidad de Huelva, 2013, pp. 71-95.

Pietschmann, H.: «Un testimonio alemán desconocido sobre el comercio y la navegación en el Atlántico: la curiosa descripción de Friedrich Martens de una navegación de Hamburgo a Cádiz en 1671-72», en Armillas Vicente, J. A. (ed.): Actas del VII Congreso Internacional de Historia de América. Ponencias y Comunicaciones. Zaragoza, 2 al 6 de julio de 1996. Zaragoza, 1998, pp. 1763-1796.

Pulido Bueno, I.: José Patiño. El inicio del gobierno político-económico ilustrado en España. Huelva, 1998.

Quintero GonzÁlez, J.: El arsenal de la Carraca (1717-1736). Madrid, 2000.

Ravina Martín, M.: El pleito Cádiz-Sevilla por la Casa de la Contratación. El Memorial de Francisco Manuel de Herrera. Cádiz, Diputación Provincial, 1984.

Reichert, R. B.: «El Caribe Centroamericano en la estrategia defensivo-militar de la Casa de los Austrias, siglos xvi y xviı», Caribbean Studies, 44:1-2, 2016, pp. 111-139.

Ricard, J. P.: Négoce d'Amsterdam. Ámsterdam, Imprenta Etienne Lucas, 1722.

Saralegui y Medina, L.: Historia del cuerpo administrativo de la Armada. El Ferrol, 1867.

SCHÄFER, E.: El Consejo Real y supremo de las Indias. Historia y organización del Consejo y de la Casa de la Contratación de las Indias. Madrid, León, Marcial Pons, Junta de Castilla y León, 2003, 2 vols.

Serrano Mangas, F.: Armadas y flotas de la plata (1620-1648). Madrid, Banco de España, 1989.

Tapias Herrero, E.: «El teniente General López Pintado, cargador a Indias, Jefe de Escuadra y marqués de Torreblanca del Aljarafe», Temas Generales, 2010, pp. 408-417.

Ediciones Universidad de Salamanca / @®@@

Stud. his., H. ${ }^{a}$ mod., 39, n. 2 (2017), pp. 75-114 
Torres SAnches, R.: La llave de todos los tesoros. La Tesorería General de Carlos III. Madrid, Sílex, 2012.

Trindade, A. R.: «Bourbon Naval Policy, Forestry and Timber Supply for Shipbuilding in Andalucia (1700-1759): Brief Introductory Research Notes», en Varela Gomes, R. (coord.): The Management of Iberian Forest Resources in the Early Modern Shipbuilding: History and Archaeology. Lisboa, IAP, 2015, pp. 57-65.

VÁzQueZ de Prada, V.: «Las rutas comerciales entre España y América en el siglo XVIII», Anuario de Estudios Americanos, XXV, 1968, pp. 197-241.

Veitia Linaje, J. de: Norte de la Contratación de las Indias Occidentales (Sevilla: Imprenta de Juan Francisco de Blas, 1672). Edición facsímil, Madrid: Instituto de Estudios Fiscales, 1981, Estudio preliminar de Francisco de Solano.

Walker, G. J.: Política española y comercio colonial, 1700-1789. Barcelona, Ariel, 1979.

Ediciones Universidad de Salamanca / 요 Stud. his., H. ${ }^{a}$ mod., 39, n. 2 (2017), pp. 75-114 